\title{
Aerosol Characteristics in the Offgas from a Pilot-Scale Sluicing Operation
}
M. W. Ligotke
G. A. Whyatt
M. R. Beckette

January 1995

Prepared for the U.S. Department of Energy under Contract DE-AC06-76RLO 1830

Pacific Northwest Laboratory

Operated for the U.S. Department of Energy by Battelle Memorial Institute 


\title{
DISCLAIMER
}

This report was prepared as an account of work sponsored by an agency of the United States Government. Neither the United States Government nor any agency thereof, nor Battelle Memorial Institute, nor any of their employees, makes any warranty, expressed or implied, or assumes any legal liability or responsibility for the accuracy, completeness, or usefulness of any information, apparatus, product, or process disclosed, or represents that its use would not infringe privately owned rights. Reference herein to any specific commercial product, process, or service by trade name, trademark, manufacturer, or otherwise does not necessarily constitute or imply its endorsement, recommendation, or favoring by the United States Government or any agency thereof, or Battelle Memorial Institute. The views and opinions of authors expressed herein do not necessarily state or reflect those of the United States Government or any agency thereof.

\author{
PACIFIC NORTHWEST LABORATORY \\ operated by \\ BATTELLE MEMORIAL INSTITUTE \\ for the \\ UNITED STATES DEPARTMENT OF ENERGY \\ under Contract DE-AC06-76RLO 1830
}

Printed in the United States of America

Available to DOE and DOE contractors from the

Office of Scientific and Technical Information, P.O. Box 62, Oak Ridge, TN 37831; prices available from (615) 576-8401. FTS 626-8401.

Available to the public from the National Technical Information Service, U.S. Department of Commerce, 5285 Port Royal Rd., Springfield, VA 22161. 


\section{DISCLAIMER}

Portions of this document may be illegible in electronic image products. Images are produced from the best available original document. 
M. W. Ligotke

G. A. Whyatt

M. R. Beckette

January 1995

Prepared for

the U.S. Department of Energy

under Contract DE-AC06-76RLO 1830

Pacific Northwest Laboratory

Richland, Washington 99352 



\section{Summary}

A pilot-scale study was performed to simulate conditions anticipated during sluicing operations to retrieve waste in single-shell Tank 241-C-106 at the U.S. Department of Energy's Hanford Site in southeastern Washington. The objective of the study was to identify and characterize the potential aerosol source term at the inlet of the headspace exhaust ventilation system during sluicing operations. The information is needed to support decisions for components to be used in the full-scale operation. A secondary objective was to qualitatively evaluate the visibility during sluicing.

Three simulated sluicing tests were performed in the 336 Building's quarter-scale waste tank facility located at Hanford. Scaling relationships were used to guide modifications to the quarterscale tank to accommodate tests that simulated tank geometry, sluicing, and ventilation conditions in the full-scale tank. Simulated sluicing fluids were targeted on solid and liquid surfaces during the tests. Test conditions were monitored, and aerosol measurements were made in the offgas ventilation duct. Also during the tests, an in-tank camera was used to monitor visibility.

During the three tests, steady aerosol concentrations were reached within 90 minutes and remained constant thereafter. Table 1 shows test results and extrapolation to the full-scale sluicing operation. Results indicate that changing the impact target made little difference in the aerosol concentration. However, adding clay (Test T03) to the sluicing fluid increased the concentration of sodium chloride aerosol. Compared with salt, the clay itself was underrepresented in the aerosol, possibly because larger clay particles or agglomerates would have been less likely to be incorporated in small aerosol particles. The wet particle sizes in the aerosol were found to be widely distributed, with particles smaller than $1 \mu \mathrm{m}$ contributing 10 to $20 \%$ of the mass concentration and particles larger than $10 \mu \mathrm{m}$ contributing 60 to $70 \%$.

Based on results of the pilot-scale tests, and using an estimated (assumed) full-scale sluicing fluid composition of $10 \mathrm{wt} \%$ soluble and $10 \mathrm{wt} \%$ insoluble solids, the aerosol concentration expected in Tank C-106 is $38 \mathrm{mg} / \mathrm{m}^{3}$ soluble solids and $17 \mathrm{mg} / \mathrm{m}^{3}$ insoluble solids. The total wet aerosol mass is expected to be approximately $360 \mathrm{mg} / \mathrm{m}^{3}$ if assumptions regarding headspace humidity (essentially saturated) and the ratio of solids to water are sufficient. A wide size distribution of particles is expected in the exhaust flow from the full-scale tank, with particles less than $1 \mu \mathrm{m}$ contributing roughly $20 \%$ of the mass concentration and particles larger than $10 \mu \mathrm{m}$ contributing $60 \%$.

Table 1. Aerosol Concentrations in the Offgases of Pilot-Scale Sluicing Tests (Measured) and Predicted Full-Scale Operations (Estimated). Solids concentrations equal mass of solids per mass of slurry.

\begin{tabular}{|c|c|c|c|c|c|}
\hline \multirow[b]{2}{*}{ Test No. } & \multicolumn{2}{|c|}{ Slurry Composition, wt\% } & \multicolumn{3}{|c|}{ Aerosol Concentration $\left(\mathrm{mg} / \mathrm{m}^{3}\right)$} \\
\hline & Soluble & Insoluble & Soluble & Insoluble & Total Wet \\
\hline \multicolumn{6}{|c|}{ Pilot-Scale Study (Measured) } \\
\hline T01 & 4.8 & $\mathrm{NA}$ & $10.6 \pm 0.5$ & NA & 220 \\
\hline T02 & 4.8 & NA & $10.5 \pm 0.4$ & NA & 220 \\
\hline T03 & 4.4 & 8.9 & $15.1 \pm 0.4$ & $14.1 \pm 0.7$ & 330 \\
\hline \multicolumn{6}{|c|}{ Full-Scale Operation (Estimated) } \\
\hline NA & 10 & 10 & 38 & 17 & 360 \\
\hline
\end{tabular}




\section{Acknowledgments}

The authors gratefully acknowledge support provided at Pacific Northwest Laboratory (PNL) by Chuck Hymas, Tony Rizzo, and Gary Dennis in preparing and operating test equipment; Lana Widrig and Bob Barberra, who provided chemical analysis of samples; and Mike Powel1, who assisted in evaluating aerosol droplet evaporation. Additional valuable assistance and guidance was provided by Paul Scott, the PNL program manager, and John Bailey, Westinghouse Hanford Company, and Paul Rice, Kaiser Engineers Hanford. Georganne O'Connor, Lila Andor, and Carol Ryder assisted with preparing this report. 



\section{Contents}

Summary $\ldots \ldots \ldots \ldots \ldots \ldots \ldots \ldots \ldots \ldots \ldots \ldots \ldots \ldots \ldots \ldots \ldots \ldots \ldots \ldots \ldots$ iii

Acknowledgments $\ldots \ldots \ldots \ldots \ldots \ldots \ldots \ldots \ldots \ldots \ldots \ldots \ldots \ldots \ldots \ldots \ldots \ldots, \quad v$

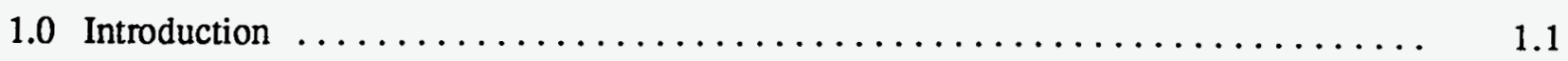

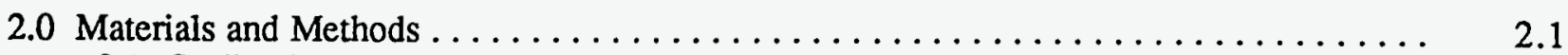

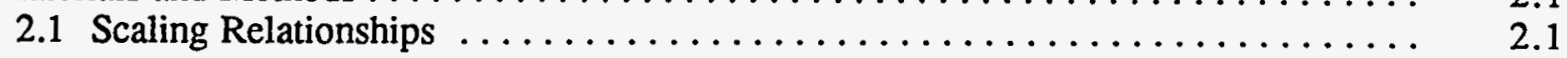

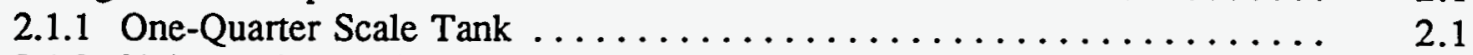

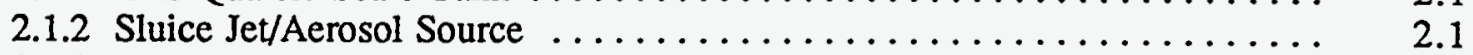

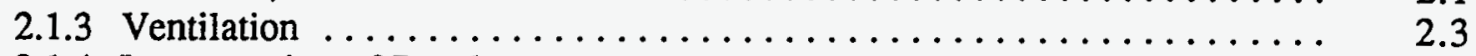

2.1.4 Interpretation of Results $\ldots \ldots \ldots \ldots \ldots \ldots \ldots \ldots \ldots \ldots \ldots \ldots \ldots \ldots \ldots \ldots$

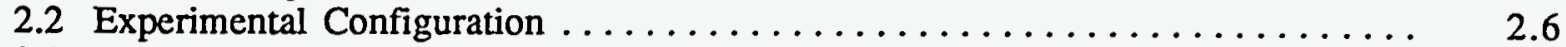

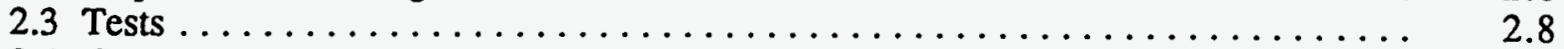

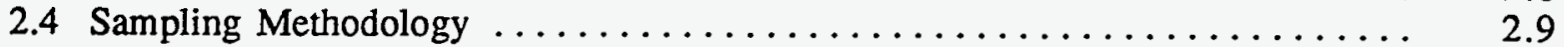

2.5 Calibrations . . . . . . . . 2.12

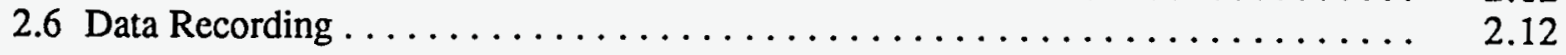

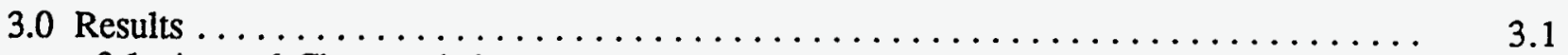

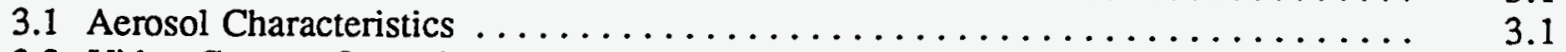

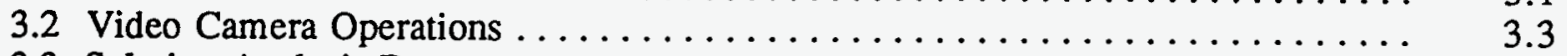

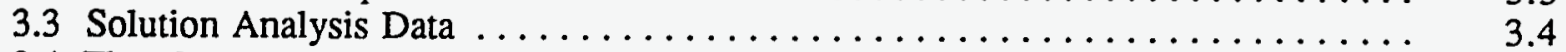

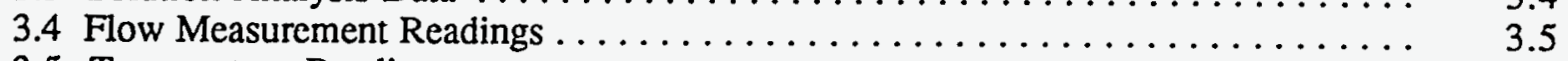

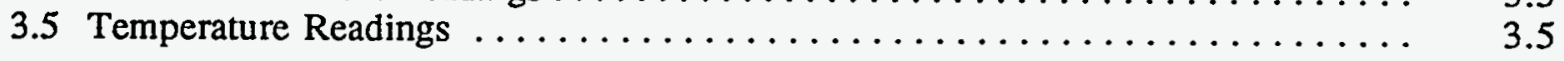

4.0 Conclusions $\ldots \ldots \ldots \ldots \ldots \ldots \ldots \ldots \ldots \ldots \ldots \ldots \ldots \ldots \ldots \ldots \ldots \ldots \ldots \ldots \ldots$

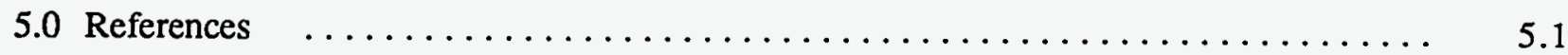

Appendix A - Relative Humidity in Full-Scaie Tank Headspace $\ldots \ldots \ldots \ldots \ldots \ldots \ldots$ A.1

Appendix B - Data Tables . . . . . . . . . . . .

Appendix C - Mass Concentration Results $\ldots \ldots \ldots \ldots \ldots \ldots \ldots \ldots \ldots \ldots \ldots \ldots \ldots$

Appendix D - Photographs . . . . . . . . . . 


\section{Figures}

2.1 Schematic of Experimental Setup and Elevated False Floor in Quarter-Scale

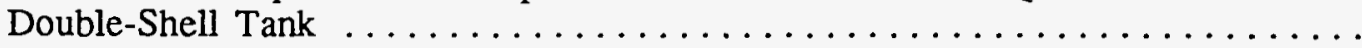

2.2 Schematic of Tank Used for Preparation of Salt Solution and Kaolin Clay Slurry . .

2.3 Schematic of Aerosol Sampling Trains $\ldots \ldots \ldots \ldots \ldots \ldots \ldots \ldots \ldots \ldots \ldots$

2.4 Calibration Curve of Magnetic Flowmeter Used to Measure Sluice Stream Flow . . . $\quad 2.13$

2.5 Anemometer Calibration Curve $\ldots \ldots \ldots \ldots \ldots \ldots \ldots \ldots \ldots \ldots \ldots \ldots \ldots \ldots \ldots$

\section{Tables}

3.1 Characteristics of Aerosols Sampled in the Exhaust Ventilation Duct from Three

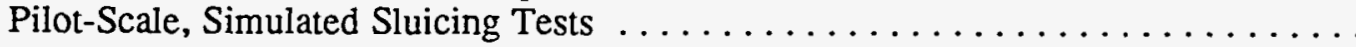

3.2 Composition of Sluicing Fluid Grab Samples as a Function of Time . . . . . . .

3.3 Flow Measurement Readings Taken During Aerosol Testing ............

3.4 Average Values of Thermocouple Readings Taken During Aerosol Testing . . . . . . . 


\subsection{Introduction}

Tank C-106, a 2,020,000-L (533,000-gal) dished-bottom, single-shell tank (SST), contains 90Srrich heat-generating sludge. The scope of Project W-320 is to mobilize and remove heat-generating sludge from Tank 241-C-106 (C-106) using past-practice sluicing. During sluicing, a concern exists that high aerosol concentrations could produce excessive radioactive contamination in the offgas treatment system. There is also a concern that the aerosols may hinder visibility and hinder effective aiming of the sluice jet. To address these concerns, Westinghouse Hanford Company (WHC) asked Pacific Northwest Laboratory (PNL)(a) to conduct the studies described here.

To perform the past-practice sluicing of Tank C-106, plans call for supernatant from AY-101 to be transferred to AY-102 and used as the sluice fluid in C-106;(b) after sluicing, the slurry will be returned to AY-102 to settle. Most of the heating is produced by $90 \mathrm{Sr}$ in the top $655,000 \mathrm{~L}$ (173,000 gal) of sludge. The depth of waste in C-106 is 1.7 to $2.0 \mathrm{~m}(5.6$ to $6.6 \mathrm{ft}$ ), and the height of the vapor space is 3.8 to $7.9 \mathrm{~m}(12.5$ to $25.9 \mathrm{ft})$. In both cases, the greater dimensions are at the center of the tank. Past practice suggests that sluicing operations will create an aerosol in the vapor space of C-106. Aerosols may be generated by the interaction of the sluicing jets with head space air, tank liquid or sludge and solid tank surfaces. The characteristics of the aerosol observed within the vapor space will depend on the generation rate, particle size distribution and settling rate, and ventilation system operation. Aerosols may impair aiming of the sluicing nozzle by degrading visibility within the tank or may deliver unacceptable radionuclide loadings to the ventilation system. Similar issues related to the waste retrieval operations are of concern to other projects (W-211 and tank farm upgrade projects such as W-061).

The objective of this study was to provide estimates of the concentrations of soluble and insoluble aerosols that might occur during sluicing of Tank C-106 and to provide information on possible visibility problems. The information generated by the testing includes the amount of soluble and insoluble solids contained in the aerosols leaving the tank and the size distribution of these aerosols. The primary objectives of this task were to provide estimates of: 1) the mass loading of soluble material leaving the Tank C-106 during sluicing; 2 ) the mass loading of insoluble solids leaving the Tank C-106 during sluicing; 3 ) the expected particle size distribution of aerosols leaving the Tank C-106 during sluicing. Also, as a secondary concern, the visibility within the tank during sluicing was evaluated using an in-tank camera to view different sized targets.(c)

Section 2.0 of this report describes materials and methods used to conduct the tests. Results are presented in Section 3.0, and conclusions are described in Section 4.0.

(a) Pacific Northwest Laboratory is operated for the U.S. DOE by Battelle Memorial Institute under Contract DE-AC06-76RLO 1830.

(b) Current plans (January 1995) call for the use of buffered water to sluice waste in Tank C-106.

(c) Beckette, M. R. 1994. Test Plan for Technical Support for Project W-320, Sluicing Retrieval for Tank 241-C-106. Pacific Northwest Laboratory, Richland, Washington. 


\subsection{Materials and Methods}

Preparations to simulate sluicing operations in Tank C-106 involved determining scaling factors that would allow use of the (modified) quarter-scale double-shell waste tank facility located in the 336 Building. After initial plans were completed, the facility was modified, and tests were performed. The following sections explain the experimental conditions that existed during testing. Details on scaling, testing, sampling, and data collection are provided.

\subsection{Scaling Relationships}

Scaling relationships were identified that allowed the quarter-scale tank to be used in the current study. The tank (spatial), sluicing jet (aerosol), and ventilation flows (mixing, residence time) were scaled to represent conditions expected to exist in C-106 during sluicing operations. Based on these relationships, information was developed that allows the test results to be used to estimate aerosol concentrations produced during actual full-scale operations that may include sluicing solutions with compositions other than those tested.

\subsubsection{One-Quarter Scale Tank}

The spatial relationships within the tank were determined using linear geometric scaling to obtain a one-quarter scale model of Tank C-106. To simulate the smaller height of the head space in a single-shell tank like C-106, a false floor was installed at a height of $180 \mathrm{~cm}(5.9 \mathrm{ft})$ above the floor. (The quarter-scale facility was designed to simulate double-shell tanks which are twice as tall as single-shell tanks.) This height was determined based on the smaller volume of Tank C-106 compared to a double shell tank, $2,020,000 \mathrm{~L}(533,000 \mathrm{gal})$ vs $3,790,000 \mathrm{~L}(1,000,000 \mathrm{gal})$, and the volume of Tank $\mathrm{C}-106$ occupied by sludge. The sludge was included in this calculation because it was anticipated that a smallcr head space would result in higher concentrations and thus would be the more conservative case. The contour formed by the scaled dome did not match the scaled contour of Tank C-106. However, the change in elevation from the top of the dome to the point at which curvature started was similar, and the differences were not thought to be significant.

The locations of the risers in the scale model did not correspond exactly with the locations at which components such as the air introduction, air removal, in-tank camera, and sluice jet penetrated the tank. Components were positioned as close to the desired locations as possible using the existing risers.

\subsubsection{Sluice Jet/Aerosol Source}

The sluice jet was scaled by matching the exit velocity and scaling the nozzle geometrically. This resulted in a liquid flow which was one-sixteenth of the full-scale flow. Exit velocity was matched to provide the same relative velocity of the jet to the air and approximately the same momentum and kinetic energy per unit volume of sluice fluid. Assuming the aerosol generation rate is proportional to the sluice jet flow volume, the generation rate at pilot-scale on a per-unit-volume of head space basis, was $64 \div 16$ or four times greater than at full-scale. However, the reduction in number concentration as a result of settling from a relatively well-mixed vessel is inversely proportional to the height of the tank. If the same uniform concentration is assumed to exist in each tank at steady state, the settling loss per unit volume would be four times greater in the quarter-scale tank. 
Therefore, the difference in generation rate per unit volume is approximately compensated for by the settling loss, and aerosol concentrations are expected to be comparable between pilot and full scale.

It was realized that aerosol generation would be possible from the interaction of the sluice jet with both the air and the target. It was believed the target interaction was the more significant. However, if the jet is pictured as a cylinder with a diameter (D) matching the diameter of the jet exit, a length to the impact point $(\mathrm{L})$, and volume flow rate $(\mathrm{Q})$, the comparison between quarter scale and full scale is the same as that obtained based on flow volume alone (i.e., $\pi D L / Q$ at the quarter scale compared with $[\pi \times 4 \mathrm{D} \times 4 \mathrm{~L} \div 64 \mathrm{Q}]$ or $\pi \mathrm{DL} / 4 \mathrm{Q}$ at full scale, resulting in one-fourth the generation rate per volume during full-scale versus pilot-scale operation).

Secondary breakup of droplets into smaller droplets contributes to the aerosol concentration by producing aerosols with small droplet sizes, reducing the settling velocity, and increasing the time over which the aerosol remains suspended in the air. Experimental data reported in the literature leads to a critical condition for the maximum droplet size that can resist secondary breakup as follows (Orr 1966):

$$
D=\frac{16 \sigma}{\rho_{B} U_{S}^{2}}
$$

where $\mathrm{D}=$ droplet diameter

$\sigma=$ surface tension of the liquid

$\rho_{g}=$ density of the gas

$\mathrm{U}_{\mathrm{r}}=$ velocity of droplet relative to air.

This equation can be used to assess the effect of key variables on the aerosol generation from secondary breakup. The exit velocity of the jets was matched, so the relative velocity in pilot and full scale should be approximately the same at both scales. The density of the gas is affected by temperature, pressure, and humidity. Under a set of assumed conditions, (a) the density of the gas in the pilotscale is expected to have been about $8 \%$ greater than what will be seen in the full-scale tank. A higher gas density should result in smaller aerosols, and thus, provide a conservatively high result in the test. The effects on surface tension are slightly more complex and are divided below into solute effects and temperature effects:

Solute Effect--Tank AY-101 supernate is a possible sluice fluid for Tank C-106.

Surface tension measurements of AY-101 are not available. However, based on the composition, an approximate value can be estimated. Representing the AY-101 composition(b) as $3.1 \mathrm{wt} \% \mathrm{Na}_{2} \mathrm{CO}_{3}, 7.8 \mathrm{wt} \% \mathrm{NaNO}_{3}, 3.35 \mathrm{wt} \% \mathrm{NaOH}$ and treating the surface tension effects as additive, leads to an estimated $6.3 \%$ increase in surface tension above that of water. The $5 \mathrm{wt} \%$ $\mathrm{NaCl}$ solution on the other hand, would be expected to have a surface tension $2.25 \%$ higher than water (based on data at $20^{\circ} \mathrm{C}$ ).

(a) Assuming 5 in. vacuum at full scale, no vacuum at pilot scale, 400 in. atmospheric pressure, $25^{\circ} \mathrm{C}$ pilot scale, $40^{\circ} \mathrm{C}$ at full scale, saturated conditions at both scales, and neglecting effects of salts on vapor pressure.

(b) Based on a 4/87 analysis of AY-101 with $19,740 \mathrm{mg} / 1 \mathrm{CO}_{3}, 63,860 \mathrm{mg} / 1 \mathrm{NO}_{3}, 14,977 \mathrm{mg} / \mathrm{OH}$. Other analytes, including $6,480 \mathrm{mg} / \mathrm{TOC}$, were neglected. 
Temperature Effect--Assuming a temperature that is $15^{\circ} \mathrm{C}$ higher in the full-scale results in a surface tension that is lowered by $3.35 \%$ (based on data for water at $40^{\circ} \mathrm{C}$ vs $25^{\circ} \mathrm{C}$ ).

Overall, the surface tension effect is $-6.3 \%+3.35 \%+2.25 \%=-0.7 \%$; therefore, the surface tension of the simulant would be expected to be approximately $1 \%$ lower than the actual sluice fluid, which should not have any significant effect.

Other variables that may have an effect include the viscosity and density of the sluice fluid. The density of the actual sluice fluid will be about $8 \%$ greater than the pilot-scale sluice stream.(a) The increased density would be expected to increase the terminal velocity for a given size aerosol droplet, which would tend to make the pilot-scale test conservative. The effect of the density on the aerosol generation rate is uncertain.

The liquid viscosity of the pilot-scale sluice system is expected to be lower despite the lower temperature. The lower liquid viscosity in the pilot-scale is believed to be conservative.

\subsubsection{Ventilation}

Ventilation flow in the quarter-scale tank was scaled to provide similar mixing and air-exchange rates (residence) times. A ventilation flow rate of $480 \mathrm{sLpm}(17 \mathrm{scfm})$, compared with the normal full-scale flow rate of $30,900 \mathrm{sLpm}$ (1090), was selected for the tests, based on the ratio of head-space volume between the scaled tank and Tank C-106 $(1090 \div 43=17 \mathrm{scfm})$.

The ventilation flow rate was removed from the scaled tank using a right-cylindrical ventilation duct that penetrated $61 \mathrm{~cm}(24 \mathrm{in}$.) below the elevation of a riser to draw air from the same relative elevation as it will be drawn from Tank C-106. However, the point at which the ventilation flow is planned to be withdrawn from Tank C-106 is actually closer to the tank wall.

The diameter of the ventilation exhaust duct in the scaled tank also varied from that planned to be used in Tank C-106. In the full-scale tank, the total ventilation flow normally exits the tank through a $62-\mathrm{cm}(24.4-\mathrm{in}$.) riser. If the ventilation exit had been scaled geometrically, it would have resulted in an exit ventilation duct of roughly $15.25 \mathrm{~cm}(6 \mathrm{in}$.) diameter. However, because the ventilation flow was scaled based on a volumetric criteria, this would have resulted in a velocity of $43 \mathrm{~cm} / \mathrm{s}$ in the scaled tank compared with the C-106 velocity of $171 \mathrm{~cm} / \mathrm{s}$. This scaled exhaust velocity would allow entrainment of droplets as large as $140 \mu \mathrm{m}$ (unit density) compared to $420 \mu \mathrm{m}$ at the full scale. On the other hand, scaling by matching the exit velocity would have resulted in a line size of approximately $7.6 \mathrm{~cm}(3 \mathrm{in}$.). The higher velocity in the smaller line size, however, created a concern that larger particles might be lost either at the entrance or in transit prior to sampling. As a compromise, a $10.8-\mathrm{cm}(4.25$-in.) line size was selected. This provided a velocity of $98 \mathrm{~cm} / \mathrm{s}$, which is sufficient to entrain up to $280 \mu \mathrm{m}$ mist droplets. In addition, the centrifugal force on the $46-\mathrm{cm}$ radius, $90^{\circ}$ bends in the ventilation duct upstream of the aerosol samplers was only $0.16 \mathrm{G}$ compared with $0.49 \mathrm{G}$ for a $7.6-\mathrm{cm}$ (3-in.) line, reducing the inertial loss of entrained droplets.

The introduction of air to the quarter-scale tank through a 4.3-cm (1.68 in.) nozzle was selected based on a full-scale flow of $24,300 \mathrm{sLpm}(860 \mathrm{scfm})$ passing through a $30.5 \mathrm{~cm}$ (12 in.)

(a) The density comparison was made between Tank AY-101 supernate without additional $\mathrm{NaOH}$ addition $\left(1.120 \mathrm{~g} / \mathrm{cm}^{3}\right)$ and $5 \mathrm{wt} \% \mathrm{NaCl}$ in water. Insoluble solids were not included in the comparison. 
pipe. The inlet was positioned at a distance of $127 \mathrm{~cm}$ (50 in.) below the top of the west riser (twothirds of the maximum distance above the false floor). Matching the exit velocity, and assuming the entire $480 \mathrm{sLpm}(17 \mathrm{scfm})$ enters through the air introduction point, results in a diameter of $4.3 \mathrm{~cm}$ (1.69 in.), which is approximately the diameter of a 1.5 -in. schedule 10 pipe or $4.3 \mathrm{~cm}$ (1.7 in.). If all air had been introduced through a 4.3-cm (1.7-in.) I.D. nozzle, the pressure drop and resulting vacuum within the tank during operation would have been on the order of 0.93 torr $(0.5 \mathrm{in}.) \mathrm{H}_{2} \mathrm{O}$ ) Inleakage from other locations in the tank is expected to have reduced this vacuum.

\subsubsection{Interpretation of Results}

Based on the scaling relationships discussed, an attempt was made to produce a one-to-one correspondence between the aerosol concentration (expressed as volume of aerosol particles per volume offgas, before any drying) in the pilot- and full-scale operations. In addition, the physical particle sizes are expected to scale approximately one-to-one (wet basis) between pilot- and full-scale. There may be some difference between the slurry and aerosol concentration of insoluble and soluble solids, especially in the very fine particle sizes. The following approach is recommended for scaling the experimental results to the expectations for Tank C-106, presuming similar headspace relative humidities exist (below).

$$
\begin{aligned}
& X_{t d}=X_{\text {sol }}+X_{\text {insol }} \\
& \mathrm{X}_{\text {sol }}=\left(\frac{\text { Test }_{\text {sol }} \mathrm{mg}}{\mathrm{m}^{3} \text { air }} * \frac{\mathrm{C106_{ \text {sol } }} \text { wt\% }}{\text { Test }_{\text {sol }} w \%}\right)\left(\frac{\rho_{\text {slurryC106 }}}{\rho_{\text {slurry test }}}\right) \\
& X_{\text {insol }}=\left(\frac{\text { Test }_{\text {insol }} \mathrm{mg}}{\mathrm{m}^{3} \text { air }} * \frac{\mathrm{C106}{ }_{\text {insol }} \mathrm{wt} \%}{\text { Test }_{\text {insol }} w \%}\right)\left(\frac{\rho_{\text {slurry C106 }}}{\rho_{\text {slurry test }}}\right)
\end{aligned}
$$

where $\quad X_{t d}=$ total $\mathrm{mg} / \mathrm{m}^{3}$ (dry aerosol basis) expected in Tank C-106

$\mathrm{X}_{\mathrm{sol}}=\mathrm{mg} / \mathrm{m}^{3}$ (dry aerosol basis) of soluble aerosol in Tank C-106

$\mathrm{X}_{\mathrm{insol}}=\mathrm{mg} / \mathrm{m}^{3}$ (dry aerosol basis) of insoluble aerosol in Tank C-106

Test $_{\text {sol }} \mathrm{mg}=\mathrm{g}$ of soluble aerosols in test (dry basis per $\mathrm{m}^{3}$ air)

$\mathrm{C} 106_{\text {sol }} \mathrm{wt} \%=\mathrm{wt} \%$ soluble in Tank $\mathrm{C}-106$ sluice stream

Test $_{\text {sol }} \mathrm{wt} \%=\mathrm{wt} \%$ soluble in pilot scale test sluice stream

Test $_{\text {insol }} \mathrm{mg}=\mathrm{mg}$ of insoluble aerosols in test (dry basis per $\mathrm{m}^{3}$ air)

$\mathrm{C}_{106}$ insol $_{\mathrm{wt}} \mathrm{w}=\mathrm{wt} \%$ insoluble solids in Tank $\mathrm{C}-106$ sluice stream

Test $_{\text {insol }} w t \%=w t \%$ insoluble solids in test sluice stream

$\rho_{\text {slurry }}$ C106 $=$ slurry density of sluice stream in Tank C-106

$\rho_{\text {slumy test }}=$ slurry density of test fluid.

To estimate the wet aerosol mass, add to this the mass of water that is associated with the soluble fraction of the aerosol. This is expressed as:

$$
X_{w}=X_{\text {sol }}+X_{\text {insol }}+\frac{X_{\text {sol }} * \mathrm{C}_{106 \mathrm{H}_{2}} \mathrm{Owt} \%}{\mathrm{C} 106 \mathrm{sol} \mathrm{wt} \%}
$$

where $\mathrm{X}_{\mathrm{tw}}$ is the total $\mathrm{mg} / \mathrm{m}^{3}$ (wet aerosol basis) expected in Tank C-106 and C-106 $\mathrm{H}_{2} \mathrm{O}$ wt\% is weight percent water in the Tank $\mathrm{C}-106$ sluice stream. 
It is recognized that there are factors introducing some conservatism that may bias the pilotscale test results high (producing greater aerosol concentrations in the scaled tests). However, the uncertainty is large enough that quantitative adjustment of observations based on test parameters is not justified. For purposes of this document, the sluice stream in Tank C-106 was assumed to be $10 \mathrm{wt} \%$ soluble solids, $10 \mathrm{wt} \%$ insoluble solids, and $80 \mathrm{wt} \%$ water. The C-106 sluice stream specific gravity was estimated to be 1.19 (AY-101 supernate specific gravity of 1.12 with $10 \mathrm{wt} \%$ solids having specific gravity of 2.5), and the specific gravity of the pilot-scale slurry in Test T03 was 1.09 (containing $4.4 \mathrm{wt} \%$ soluble solids and $8.9 \mathrm{wt} \%$ insoluble solids). For purposes of estimating fullscale conditions, the slurry densities were taken as representative of wet aerosol particle densities. Because insoluble particles may be underrepresented in the aerosol, this assumption may introduce minor errors. In addition, the composition and density values affect the estimate of the aerosol concentration in Tank C-106 during sluicing.

The relative humidity that will be experienced during sluicing is not known. Estimates of the expected in-tank relative humidity, without sluicing, range from about 55\% to near $100 \%$ (Appendix A). It is speculated, but not proven, that the relative humidity in the tank headspace during sluicing operations would exceed that during normal operations. The relative humidity observed during scaled sluicing tests was near saturation. If, for some reason, the relative humidity in the tank headspace during sluicing is lower(a) than that during scaled testing (nearly saturated), shrinkage of aerosol particles would occur. This would result in decreased settling velocity and increased concentration of suspended radionuclides. The extent of aerosol shrinkage is limited by the increase in ionic strength of the aerosol droplets as the water evaporates. Calculations performed to evaluate this effect for AY-101 supernate indicated that the effect would be very small at high humidities (8\% reduction in aerodynamic diameter at $90 \%$ relative humidity) and greater at low humidities (up to $37 \%$ reduction in aerodynamic diameter at $40 \%$ relative humidity). Particle shrinkage under conditions bracketed by these two cases could cause increases in aerosol concentration(b) ranging between about 1.2- and 2.6-fold, respectively, compared to the aerodynamic sizes upon generation. The Kelvin effect was investigated and found to be negligible for aerosols greater than $1 \mu \mathrm{m}$ diameter and of minor significance down to $0.1 \mu \mathrm{m}$.

For a dilute sluice solution, the extent of shrinkage is expected to be greater. Calculations indicated that aerosols of a very dilute $\left(0.05 \mathrm{M} \mathrm{NaOH}, 0.011 \mathrm{M} \mathrm{NaNO}_{2}\right)$ solution could experience $81 \%$ reduction in aerodynamic size at $40 \%$ relative humidity. Although this implies a 28 -fold increase over the concentration predicted using the initial aerosol sizes, a dilute solution would also contain lower radionuclide concentrations such that the increase would be 28 times a relatively small quantity(c). Droplets that contain significant quantities of radionuclides will also contain sludge interstitial salt solution, which will reduce the amount of shrinkage. For example, droplets

(a) Lower to an extent greater than the difference in vapor pressure depression caused by the ionic strength of the two sluicing solutions. At equal relative humidities the full-scale aerosol particles would be larger, resulting in lower concentrations of suspended radionuclides.

(b) For aerosol particles in the size range of interest, settling velocity is proportional to the square of the aerodynamic diameter. If the aerosol concentration is assumed to be inversely proportional to the settling velocity, it follows that aerosol concentration is inversely proportional to the square of aerodynamic diameter. The validity of this relationship has not been demonstrated.

(c) Aerosol droplets that contain radionuclides will also contain salts from the sludge interstitial liquid. The salts will depress the water vapor pressure and limit droplet shrinkage. Droplets that contain less salt will shrink more but will also contain less sludge solids and, therefore, less radionuclides. 
composed of 80 vol\% inhibited water (composition given above) and 20 vol\% sludge are predicted to shrink to a $40 \mu \mathrm{m}$ rather than $19 \mu \mathrm{m}$ aerodynamic diameter because of the sludge interstitial salt solution.

Based on the calculation of the effect of humidity on extent of droplet shrinkage, tank headspace humidity during sluicing may have a significant effect on radionuclide aerosol concentration. However, there is too much uncertainty in the expected tank humidity to allow adjustment of the pilot-scale sluicing test results for the effect of droplet shrinkage. In the event near-saturated conditions occur, droplet shrinkage would not have any impact.

\subsection{Experimental Configuration}

Testing was performed using the quarter-scale double-shell tank test facility located in the 336 Building. Figure 2.1 shows a schematic of the experimental setup in the quarter-scale tank. The tank has an inside diameter of $5.7 \mathrm{~m}(18.7 \mathrm{ft})$ and has a side wall height of $2.4 \mathrm{~m}(7.9 \mathrm{ft})$. Because the tank is a scaled version of a one-million gallon double-shell waste tank, and C-106 has a capacity of $2,020,000 \mathrm{~L}(533,000 \mathrm{gal})$, a false floor was constructed at a height of $180 \mathrm{~cm}$ (5 ft 11 in.) to obtain a tank head space closer to the scaled dimensions of the head space of Tank C-106, including the height of sludge.

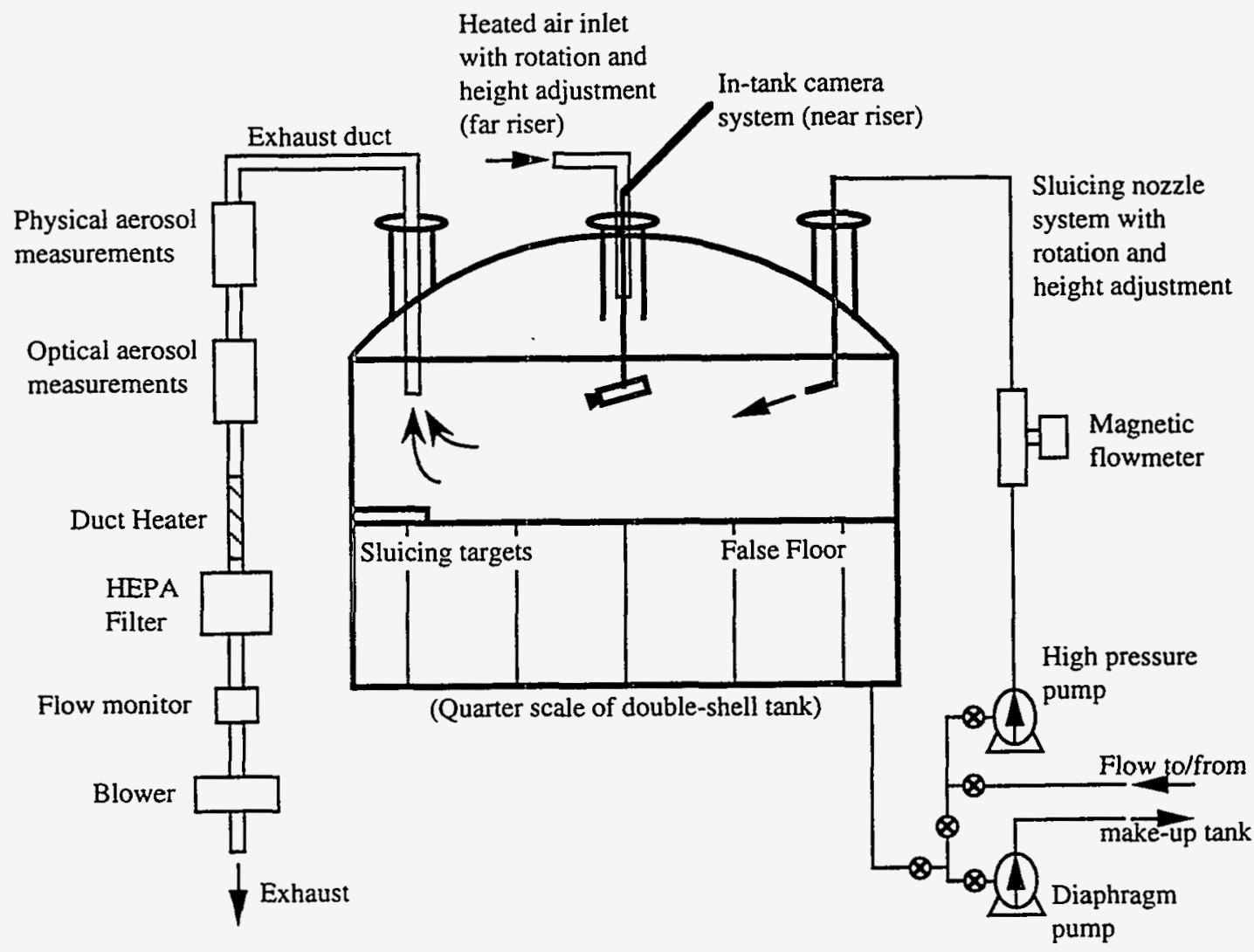

Figure 2.1. Schematic of Experimental Setup and Elevated False Floor in a Quarter-Scale Double-Shell Tank 
The floor installed in the scaled tank consisted of aluminum sheeting supported by steel livestock fencing. A shallow pan and flat steel plate (sluicing targets) were oriented horizontally at the level of the false floor on the south side of the tank. The pan simulated the sluice jet striking a liquid surface. During Test T02, the pan allowed the sluice jet to strike liquid with about a 5 to $10 \mathrm{~cm}$ depth. The horizontal steel plate simulated the sluice jet striking a hard sludge or tank surface (Tests T01 and T03). Because of the logistics of providing a sludge layer to support extended sluicing, no sluicing of sludge was performed during the three tests.

A salt $(\mathrm{NaCl})$ solution and kaolin clay simulant were prepared in the sludge tank using a diaphragm pump as shown in Figure 2.2. The water was circulated from the bottom of the tank back to the top of the tank while the sparge ring was operated and salt or kaolin clay was added from bags to the tank. The salt was added to the tank by dumping directly into the top of the tank. The clay was added by lowering a bin into the tank above the liquid surface and sluicing the clay into the tank. The fluid was then pumped until the salt was dissolved or the clay was dispersed.

The salt solution was transferred to the quarter-scale tank and then recirculated from the tank drain through the sluice nozzle using a multi-stage centrifugal pump (the high-pressure pump, Figure 2.1). When testing with the kaolin slurry, this setup was altered to reduce the extent of settling losses from the slurry. The multi-stage centrifugal pump was used to pump the slurry from the sludge tank through the sluice nozzle. The diaphragm pump simultaneously pumped the slurry out of the quarter-scale tank back into the sludge tank to conserve slurry volume. Agitation was provided in the sludge tank using the sparge ring.

The sluice fluid in the test was pumped through a $6.4 \mathrm{~mm}(1 / 4 \mathrm{in}$.) diameter, geometrically scaled sluice nozzle at $83 \mathrm{Lpm}(22 \mathrm{gpm}$ ) (see Figure 2.1). The sluice nozzle was installed in the north riser and had height and rotation adjustments to allow aiming. The quarter-scale tank was not insulated, and the sluice stream was not heated (other than by what was generated by the mechanical energy of the pump).

The sluice jet was aimed at either the flat plate target or the liquid-filled pan located at the opposite edge of the tank by viewing through a plexiglass viewport on top of the tank. In addition to the plexiglass viewport located at the top center of the tank, a camera was located in the east riser $90^{\circ}$ from the sluice nozzle. Visual targets were placed along the west wall to allow qualitative evaluation of the visibility within the tank. The visual targets consisted of four black circles on a white background and four rust-colored circles on a grey background. The targets were positioned approximately $4.6 \mathrm{~m}(15 \mathrm{ft})$ from the camera and were $5.08 \mathrm{~cm}, 2.54 \mathrm{~cm}, 1.27 \mathrm{~cm}$, and $0.63 \mathrm{~cm}(2 \mathrm{in} ., 1 \mathrm{in}$., $1 / 2$ in., and $1 / 4$ in.) in diameter. The corresponding angular displacements of the targets were $0.64^{\circ}$, $0.32^{\circ}, 0.16^{\circ}$ and $0.08^{\circ}$.

A ventilation flow rate of $480 \mathrm{sLpm}(17 \mathrm{scfm})$ was withdrawn from the south riser of the quarter-scale tank during the sluicing tests. Rather than condense the moisture from a portion of the ventilation flow and retum it to the tank, as is planned for sluicing operations in C-106, the exhaust flow was not returned to the tank. An inlet for unfiltered ambient air was located in the west riser. The inlet flow of air was not measured quantitatively; however, qualitative observations indicated that the flow was less than a quarter of the flow in the exhaust ventilation system, indicating that air leaks occurred along tank dome seams. At the west riser, the air passing into the tank through the inlet pipe was warmed slightly using an external wrap of heat tape. The air inlet nozzle was positioned $127 \mathrm{~cm}$ (50 in.) below the top of the riser with a fixed angle of $15^{\circ}$ below the horizontal. Although the air inlet had height and rotation capability, such control was not used during the tests. Rather, the inlet air was aimed in a single direction, toward the sluice jet nozzle. 


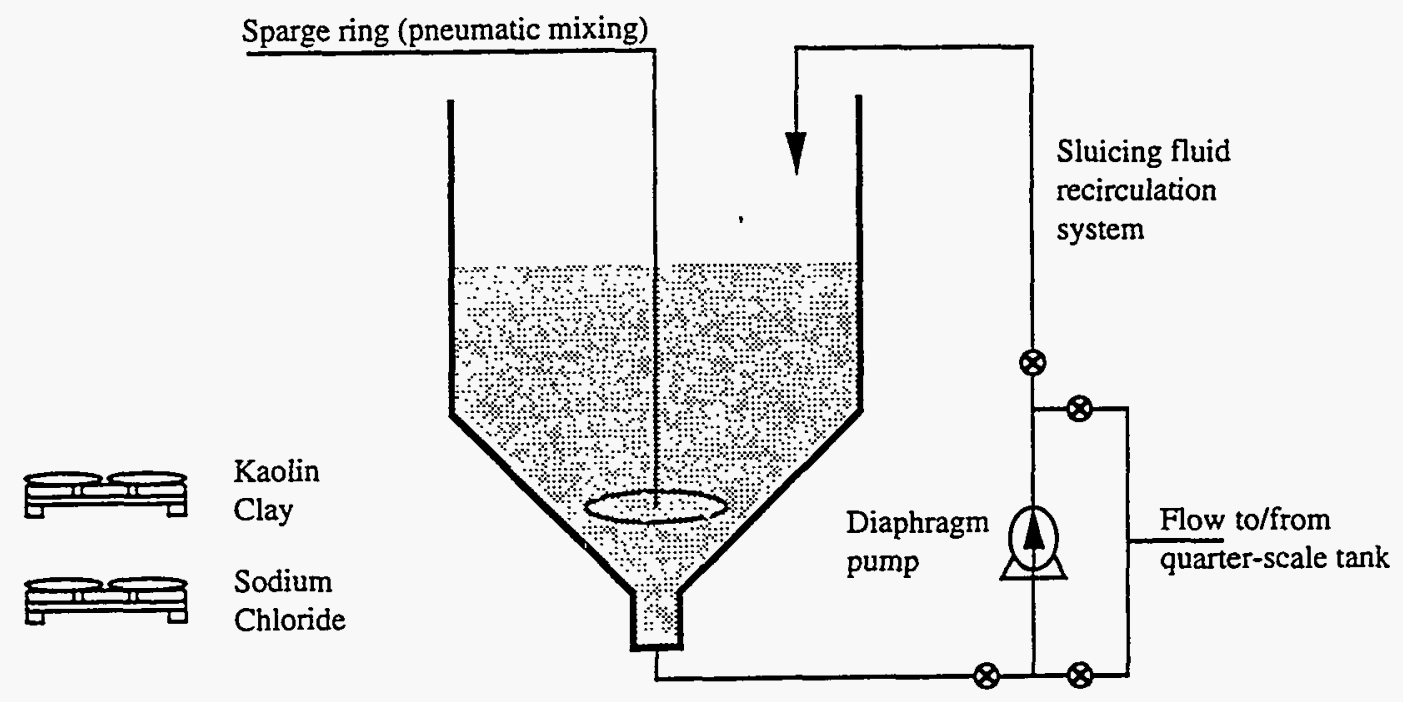

(Sludge tank used to prepare sluicing fluids)

Figure 2.2. Schematic of Tank Used for Preparation of Salt Solution and Kaolin Clay Slurry

The ventilation flow out of the tank was withdrawn vertically upward through a $10.8-\mathrm{cm}$ diameter (4.25-in.) circular duct exiting the tank near the outer edge of the south riser. The inlet of the exhaust duct was located $61 \mathrm{~cm}(24 \mathrm{in}$.) below the level of the riser flange to provide a system similar to that planned for the full-scale ventilation system in Tank C-106. After exiting the riser, the exhaust flow passed through two closely spaced $46-\mathrm{cm}$-radius, $90^{\circ}$ bends used to orient the flow downward. A welded tube allowed aerosol sample probes to be inserted vertically upward into the center of the downward-directed exhaust flow. Downstream of the sampling probe, the exhaust ductwork was directed horizontally away from the tank using a similar $90^{\circ}$ bend. The horizontally directed exhaust flow next passed through an expanded section that contained an optical aerosol monitor, and then via a heated duct to an in-line high-efficiency particle air (HEPA) filter.

After passing the filter, the flow was directed past a anemometer (velocity sensor) and exhausted into the room using an adjustable-rate blower. The in-line filter was not needed for personnel safety, but was used to remove residual aerosol particles that could otherwise have affected the anemometer. The duct upstream of the filter was heated to prevent condensation on the filter substrate. A controller was used to manually adjust the exhaust flow rate, based on the signal provided by the velocity sensor. The thermocouples were placed to monitor the sluice stream, head space, air inlet, and before and after the filter.

\subsection{Tests}

Three separate sluicing tests, T01, T02, and T03, were performed to evaluate the resulting aerosol characteristics in the offgas. The first test used a nominal $5 \mathrm{wt} \%$ salt solution, which was targeted at a steel plate; the second test used the same salt solution targeted at a sluicing fluid-filled steel pan; and the third test used the same solution with the addition of approximately $10 \mathrm{wt} \%$ kaolin 
clay and the sluicing jet targeted at the steel plate (T03). It was anticipated that different aerosol generation rates might result from different sluicing targets as well as the different sluicing fluid compositions.

Grab samples were taken from the sluicing fluid at 20- to 30-minute intervals from the vertical pipe leading to the nozzle. Multiple samples were taken for two reasons: to 1) compare the composition of the sluicing fluid with measured aerosol characteristics, and 2) determine if significant solids settling occurred in the lines.

Aerosol sample trains employing heated and ambient-temperature probes were used to characterize aerosols in the exhaust flow duct. Figure 2.3 shows the sample trains. Both filters and cascade impactors were used to collect aerosol samples. A condenser/desiccant system trapped water vapor, and a mass flowmeter indicated sample flow rates. It should be noted that the $480 \mathrm{sLpm}$ exhaust flow rate was not adjusted when the 13-sLpm aerosol samples were being obtained. The resulting $3 \%$ increase in exhaust flow rate did not affect test conditions.

Still pictures were taken as equipment was being installed. The in-tank video camera system was installed with a 24-mm lens. Various in-tank objects (nozzle, inlet pipe, circular targets, steel pan and plate) were targeted to determine proper lighting and lens size. The tests were videotaped intermittently to show the operation of the sluice nozzle and jet impaction site, and to quantify visibility during testing. During the video coverage, the camera altemated between the colored circular targets, steel pan and plate, nozzle, exit ventilation duct, inlet ventilation line, and dome lid. A plexiglass port was installed on top of the tank for direct observations. Two videotapes and a narration were produced to record additional information and comments during testing. The narration relates the elapsed tape time and the chronological testing times. The videos were sent to the project technical contact, Mr. J. W. Bailey (WHC). The videotapes produced during the study were labeled "SSE 300AERO-94-03, Project W-320, Quarter-Scale Aerosol Testing, Tape No. 1, Test No. 1, 7/20/94" and "SSE 300-AERO-94-03, Project W-320, Quarter-Scale Aerosol Testing, Tape No. 2, Test No. 1, 2, 3, and Lens Test Date, 7/20 - 7/22/94."

\subsection{Sampling Methodology}

Aerosols were physically sampled and optically monitored within the exhaust flow ductwork during tests of simulated sluicing operations performed in the modified quarter-scale tank. Sampling probes were inserted singly into the downward-directed exhaust flow from the tank as described in Section 2.2. An optical aerosol monitor was used downstream of the sample point to provide a realtime indication of particle concentration. The sampling probes consisted of $1.37 \mathrm{~m}$ (54 in.) long, $1.90 \mathrm{~cm}$ diameter (3/4 in.) stainless steel tubing (ID equal $1.52 \mathrm{~cm}[0.60 \mathrm{in}$.$] ); one probe was equip-$ ped with temperature-controlled heat tape, and the other was unheated and used for ambient temperature sampling. Each probe had a beveled leading edge, or nozzle, to minimize turbulence in the sampled gas stream. The aerosol sampling probes were connected sequentially to filter holders or particle impactors. Aerosol samples were obtained by drawing 13 sLpm flow rates through the probe, sampler, condenser, desiccant, and Sierra Model 840 Mark III-13 mass flowmeter (Sierra Instruments, Carmel Valley, California). Standard conditions were defined as $21.1^{\circ} \mathrm{C}$ and 760 torr. The sample flow rate was selected to approximate isokinetic sampling conditions. (Isokinetic sampling conditions are achieved when air velocities within the nozzle equal those in the gas stream being sampled.) This condition minimizes collecting either over- or underrepresentative aerosol samples. The condenser and desiccant trap were used to collect the water present in the sample line before passing the dried air through the mass flowmeter. The condenser consisted of a 4-L filtration flask set in an ice-water 


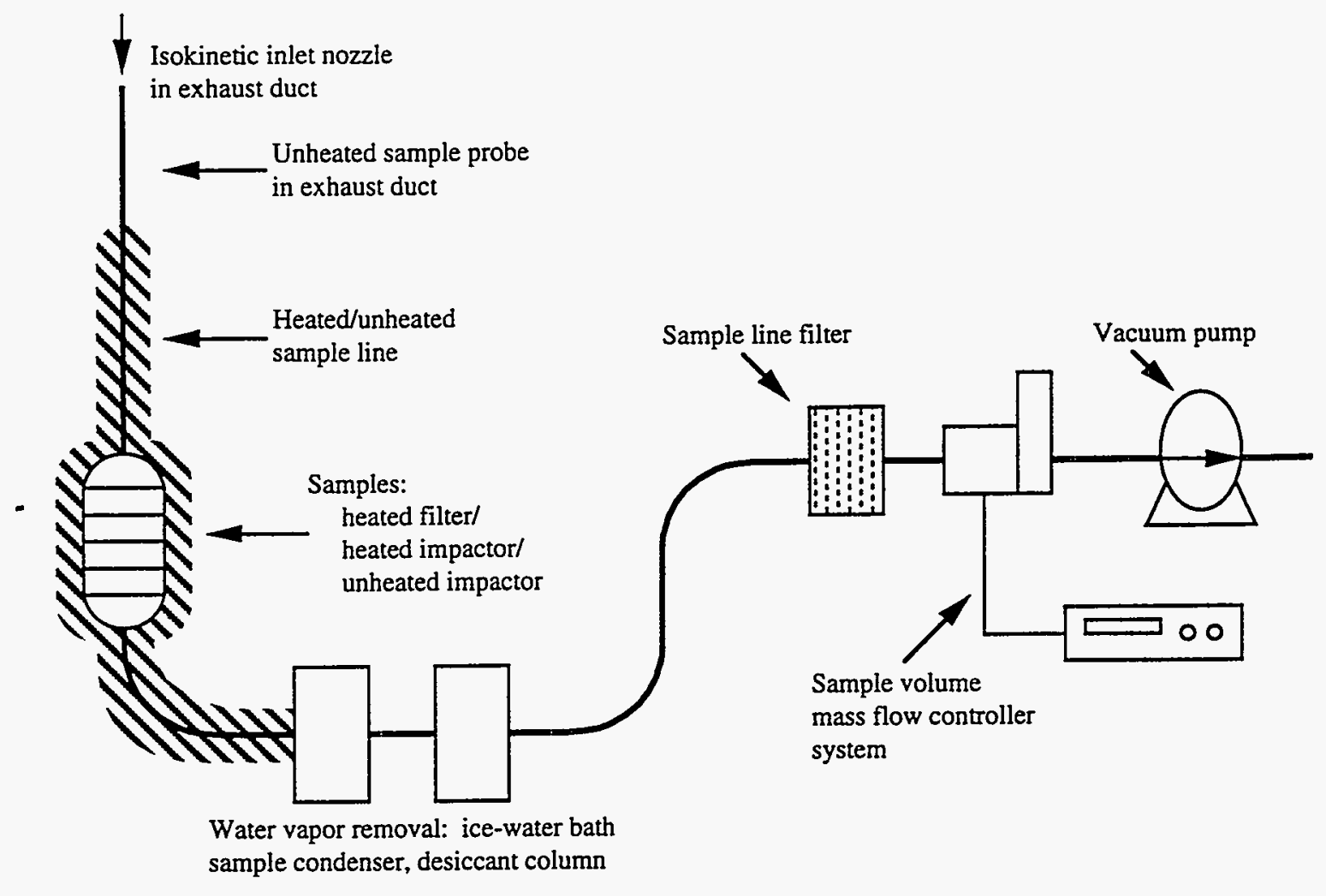

Figure 2.3. Schematic of Aerosol Sampling Trains

bath. The masses of the condenser and desiccant trap were recorded at the beginning of each test and after each aerosol sample to obtain information on the water content present in the sample streams.

High-efficiency Gelman Type A/E glass fiber filters (Gelman Sciences, Ann Arbor, Michigan) were used to measure the soluble- and insoluble-material ( $\mathrm{NaCl}$ and clay, respectively) dry aerosol mass concentrations present in the exhaust flow from the quarter-scale tank vapor space. The filters were held in Gelman 47-mm stainless steel in-line filter holders. All filter samples were obtained using the heated sampling probe. The probe was heated to provide a dry aerosol at the filter substrate. In addition, the filter holders were heated and insulated to prevent recondensation of water vapor on the filter substrate. Trial tests indicated the gas temperature at the filter was about $100^{\circ} \mathrm{C}$. The internal temperature of the filter holders was 99 to $118^{\circ} \mathrm{C}$ before and after sampling. Condensation of water vapor on filter substrate was not expected at temperatures greater than $40^{\circ} \mathrm{C}$. Sample durations were 10 and $20 \mathrm{~min}$ to optimize the collection of particles and analysis of filters for aerosol concentrations between 5 and $500 \mathrm{mg} / \mathrm{m}^{3}$.

Two Andersen Ambient cascade impactors (Graesby-Andersen, Atlanta, Georgia) were used to measure the size distribution of aerosol particles present in the exhaust flow. The impactors were operated with lightly lubricated Viton O-rings and at flow rates of 13.3 and $16.5 \mathrm{aLpm}$; the flow rates used were less than the nominal $28 \mathrm{Lpm}$ flow rate in an attempt to increase the particle size range of the results and to retain isokinetic sampling conditions at the sample nozzle. The impactors consisted of a series of eight orifice plates used to impact particles at increasing velocities onto 81 -mm flat glass 
fiber filter substrate. The substrate were held on trays immediately under each orifice plate. Submicrometer particles not collected under the orifice plates were collected on a back-up filter. One impactor was heated and attached to the heated probe to measure the size distribution of dried particles. The second impactor was operated at ambient temperature to measure the size of aerosol droplets in the exhaust flow. The temperature of air entering the heated impactor, measured before testing, was about $100^{\circ} \mathrm{C}$, and the skin temperature of the heated impactor, measured before and after each test, was 94 to $108^{\circ} \mathrm{C}$. As with the filter samples, the heated impactor was insulated and heated slowly for more than $2 \mathrm{hr}$ before sampling. The particle size range for the heated impactor was 0.6 to $15 \mu \mathrm{m}$, that for the ambient-temperature impactor was 0.7 to $16 \mu \mathrm{m}$. Sample durations were 4.0 , 10.0 , and $20.0 \mathrm{~min}$. They were estimated before the tests based on assumed aerosol concentration ranges. The ambient-temperature impactor was generally sampled for shorter durations than the heated impactor to avoid overloading stages with deposited water droplets.

Both filter and impactor aerosol samples were analyzed gravimetrically and chemically for chloride ion. In addition, the internal surfaces of the sampling probes and the top stage of the impactors were rinsed with water after selected tests and submitted for chemical analysis. Dried filter and impactor substrate were analyzed gravimetrically, and represented total soluble and insoluble material collected on each sample. Chemical analyses performed to determine the mass of chloride in each sample provided a measure of soluble material mass. The total mass of soluble material present in the probe or plate rinses was determined by multiplying the concentration of material by the total volume of rinse water.

The optical aerosol monitor operated downstream of the filter and impactor sample probes was an Industrial Dust Sampler (IDS-10) manufactured by MIE (Monitoring Instruments for the Environment, Inc., Billerica, Massachusetts). The monitor uses forward scatter between 45 and $95^{\circ}$ from a pulsed infrared light source to indicate aerosol mass concentration based on the properties and characteristics of a calibration aerosol, it is optimized for particles in the $1-10 \mu \mathrm{m}$ size range. When used to measure aerosols having different light-scattering characteristics, the monitor produces an output signal related to relative aerosol mass concentration for concentrations between about 0.1 and $1000 \mathrm{mg} / \mathrm{m}^{3}$. The instrument was operated inverted, with the optical windows at the top, to reduce the potential for obscuration caused by deposited particles. The $0-$ to $1-\mathrm{v} \mathrm{dc}$ analog signal output of the instrument was connected to a voltmeter and a strip-chart recorder, and was also recorded manually. The instrument zero was confirmed before and after each test. The instrument was used to provide a real-time indication of relative aerosol mass concentration and to indicate approximately when steady-state concentrations were achieved.

Aerosol sampling during the three sluicing tests was performed using the same sequence of measurements. Sampling was begun approximately $90 \mathrm{~min}$ after the initiation of sluicing. The sequence of sampling was F01, F02, I01, F03, I02, and F04, where "F" indicates a 47-mm filter and "I" indicates a cascade impactor. The heated sample probe was used for all samples other than 102 , which was obtained using the ambient temperature probe. When probes were not connected to samples, or when probes were switched, the access port was covered with tape to prevent leakage of air into the exhaust ventilation system. Ten minutes after the sluicing nozzle was shut off at the end of Test T03, the heated sample F05 was obtained using the heated probe to provide an indication of the rate of attenuation of aerosol mass concentration after the aerosol source term was stopped. Subsequent to F05, the probe was removed from the exhaust duct, and heated filter sample F06 was obtained using the heated probe positioned to sample ambient air. 


\subsection{Calibrations}

The magnetic flowmeter for monitoring the sluice jet flow and the anemometer for monitoring the ventilation flow were user calibrated before testing. The magnetic flowmeter used (serial no. 1941-000771886) was calibrated on July 10,1994, by weighing the amount of water accumulated in a container over a known period of time and given flow setting. The calculated flow rate (gpm) was fitted as a straight line as a function of the flowmeter setting (\%). The results from this calibration are shown in Figure 2.4.

The calibration of the anemometer was checked on July 20,1994. The anemometer (an Omega velocity flowmeter) was compared to a Sierra mass flowmeter. The air flow was provided by an adjustable blower while readings were taken from the Sierra mass flowmeter and Omega velocity flowmeter. The Sierra mass flowmeter (serial ID 515-28-03-018) had been calibrated on February 13, 1992. A correlation, shown as Figure 2.5, was developed to compare the output of these two instruments.

A mass flow controller ( 0 to $30 \mathrm{sLpm}$ ) was used to control the sampling flow rate. This device was calibrated by the WHC standards laboratory. Thermocouples were used to monitor the process temperatures. Ice baths and boiling water baths were used to verify calibration of the thermocouples.

\subsection{Data Recording}

Data were recorded in a laboratory record book or on data sheets during testing. Sampling information for grab samples, condenser samples, and desiccant samples were recorded on sample logs. Copies of the data sheets are provided in Appendix C.

The voltage readings observed from the MIE optical unit were recorded on both a data sheet and a chart recorder. The sampling times (in real time) of the filters and impactors were also recorded on data sheets. These readings were used to determine approximately when steady-state aerosol concentrations were reached. Aerosol sampling was initiated 102, 90, and $87 \mathrm{~min}$ after sluicing began during Tests T01, T02, and T03, respectively.

Data were recorded at 20- to 30-min intervals on separate data sheets to monitor flows and temperatures. Variables monitored included the temperatures of the sluice stream, head space, air inlet, and locations upstream and downstream of the HEPA filter, before and after the filter, the flow of the sluice stream, and the air velocity in the ventilation duct. The settings of the anemometer and flowmeter, respectively, were pre-determined based on scaling. A separate data sheet was provided to record the volumetric flow rate of the mass flow controller (flow and totalizer) and the weights of water collected in both the condenser and desiccant. 
Calibration Curve for Finwmeter \# 1941-00071886

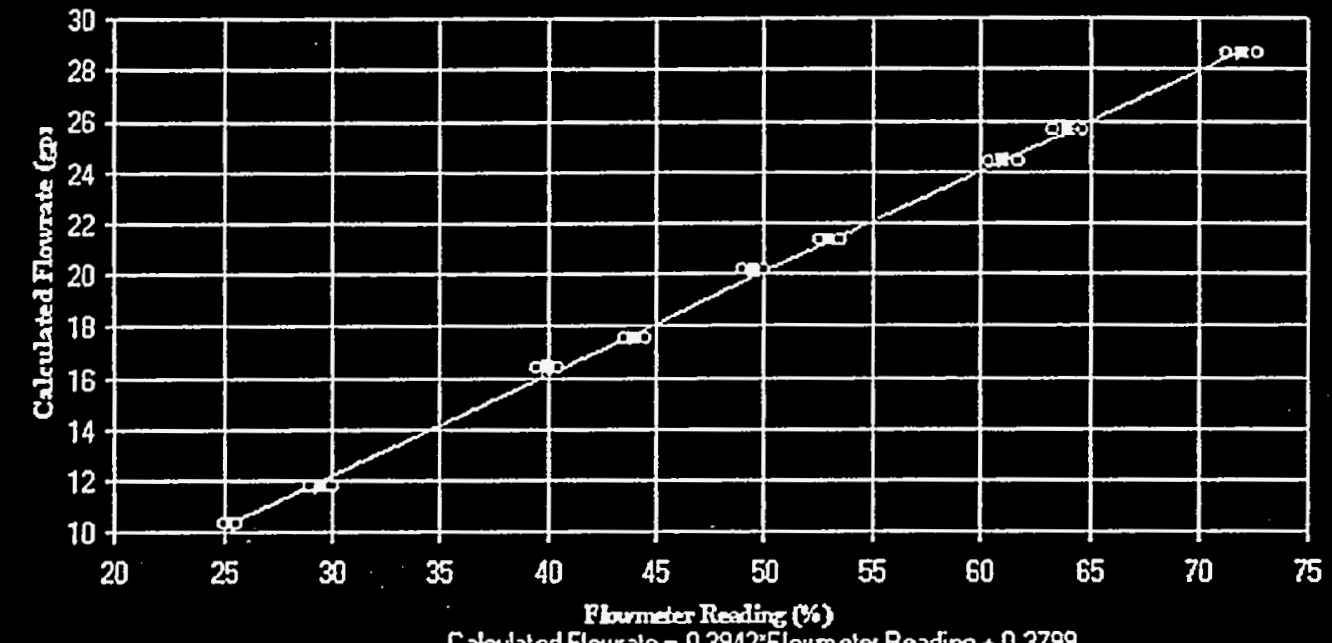

Calculated Flowale $=0.3942^{2}$ Flowm let Reading +0.3799

Figure 2.4. Calibration Curve of Magnetic Flowmeter Used to Measure Sluice Stream Flow

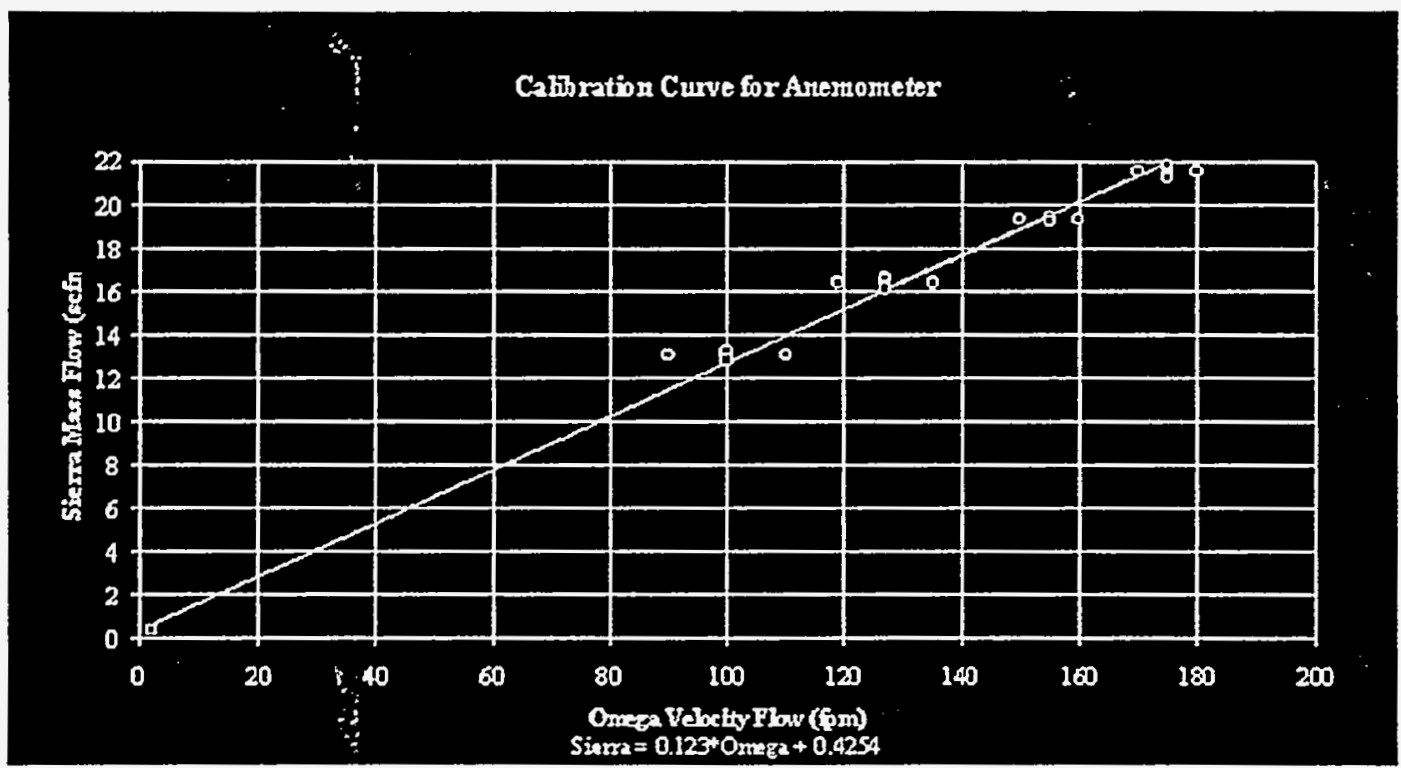

Figure 2.5. Anemometer Calibration Curve 


\subsection{Results}

This section describes the results of the three sluicing tests performed at one-quarter scale for measured aerosol characteristics, video camera operation, sluicing fluid composition, flow rates, and temperatures.

\subsection{Aerosol Characteristics}

Aerosols produced during three pilot-scale, simulated sluicing operations consisted of droplets containing salt and water (Tests T01 and T02) or salt, clay, and water (Test T03). The characteristics of these aerosols were measured using sampling probes inserted into the exhaust ventilation duct. The measurements indicated that aerosol mass concentrations increased from near-zero to steady levels within $90 \mathrm{~min}$ after sluicing began. Dry aerosol mass concentrations were determined from isokinetic filter samples and were based on the mass of salt or salt and clay collected on the filters. Dry and wet aerosol particle size data were obtained using cascade impactors. Information on the wet aerosol mass concentration (including the mass of liquid water in the droplets), generated by measuring the total water content of samples and particle size distributions, was found to be insufficient to provide accurate results. In lieu of a direct measurement, estimates of total wet aerosol mass concentration were made based on wet aerosol particle size distributions and the composition of the sluicing fluid.

Aerosol mass concentration results were corrected for the mass of particles collected by the inner walls of the sampling probe upstream of the collection substrate. Triple rinses of the heated sample probe were performed after each test, and the rinses were analyzed for chloride. The multiple rinses indicated nearly all deposited chloride was removed by the first rinse. Probe losses were determined for each test as the chloride mass collected in the probes divided by the chloride mass collectors on the samples. For Tests T01, T02, and T03, probe losses were $4.9,3.5$, and $4.4 \%$, respectively. Consequently, the gravimetric and chloride masses on each filter were adjusted by multiplying the raw data by correction factors of $1.049,1.035$, and 1.044 for Tests T01, T02, and T03, respectively. Because the distribution of particle sizes deposited to the probe was not known, the correction factor was applied only to the total mass collected in the heated cascade impactor samples and not to individual stages. The correction factors for the unheated, ambient temperature sample probe were larger (influenced by the larger size of non-evaporated particles and lack of a thermophoretic force from the walls of the heated probe); correction factors of $1.17,1.17$, and 1.13 were applied to the total quantity of material collected in the ambient temperature cascade impactor during Tests T01, $\mathrm{T} 02$, and T03, respectively.

Aerosol test results are summarized in Table 3.1 and provided in greater detail in Appendix C. The aerosol mass concentrations and particle size distributions were similar during Tests T01 and T02 despite targeting the sluicing jet on a flat steel plate during Test T01 and on a pan of sluicing fluid during Test T02. This apparent insensitivity to target type may indicate that aerosol formation from the jet dominates aerosol production; however, this interpretation of the results is not certain. Aerosol mass concentrations based on the analysis of filters for chloride were nearly identical to those obtained gravimetrically. For Tests T01 and T02, the concentrations of $\mathrm{NaCl}$ were $11.2 \pm 0.2$ and $10.9 \pm 0.0 \mathrm{mg} / \mathrm{m}^{3}$, respectively (results provided in Appendix C). 
Table 3.1. Characteristics of Aerosols Sampled in the Exhaust Ventilation Duct from Three Pilot-Scale, Simulated Sluicing Tests(a)

\begin{tabular}{|c|c|c|c|c|c|}
\hline \multirow[b]{2}{*}{$\begin{array}{l}\text { Sluicing } \\
\text { Fluid }\end{array}$} & \multirow[b]{2}{*}{ Target } & \multicolumn{2}{|c|}{ Aerosol Concentration } & \multicolumn{2}{|c|}{ Aerosol Size Distribution } \\
\hline & & $\begin{array}{c}\text { Dry } \\
\left(\mathrm{mg} / \mathrm{m}^{3}\right)\end{array}$ & $\begin{array}{c}\text { Estimated Wet } \\
\left(\mathrm{mg} / \mathrm{m}^{3}\right) \\
\end{array}$ & $\begin{array}{l}\text { Dry } \\
(\mu \mathrm{m})\end{array}$ & $\begin{array}{l}\text { Wet } \\
(\mu \mathrm{m})\end{array}$ \\
\hline $4.8 \%$ salt(a) & Plate & $10.6 \pm 0.5(b)$ & 220 & $4(c)$ & $>16$ \\
\hline $4.8 \%$ salt & Liquid & $10.5 \pm 0.4$ & 220 & 5 & $>16$ \\
\hline $\begin{array}{l}4.8 \% \text { salt }+ \\
8.9 \% \text { clay }\end{array}$ & Plate & $29.2 \pm 1.1$ & 330 & 4 & $10-16$ \\
\hline
\end{tabular}

(a) Salt weight percentage equals mass of salt per mass of salt + water. Clay weight percentage equals mass of clay per mass of salt + clay + water.

(b) Dry aerosol mass concentrations for each test equal the gravimetric average of all four samples plus/minus one standard deviation of the average. Uncertainties, based on assumed uncertainties in the measurement of mass, flow rate, and sample duration, were $\pm 5 \%$ (T01) and $\pm 3 \%$ (T02 and T03) of the individual sample results.

(c) Aerosol size distributions are shown as the aerodynamic mass median diameter, in $\mu \mathrm{m}$. The geometric standard deviations of the aerosols were estimated to be between 4 and 5 , indicating the presence of widely distributed particle sizes.

Results from Test T03, performed after adding $\sim 10 \%$ clay to the $\sim 5 \%$ salt sluicing fluid, varied from the results of Tests T01 and T02. The dry aerosol mass concentration determined gravimetrically was $29.2 \pm 1.1 \mathrm{mg} / \mathrm{m}^{3}$, which was about 3 -fold greater than the concentrations during Tests $\mathrm{TO} 1$ and $\mathrm{T} 02$. In addition, the chloride analyses indicated the concentration of $\mathrm{NaCl}$, at $15.1 \pm$ $0.4 \mathrm{mg} / \mathrm{m}^{3}$, was about 1.4 -fold greater than in the previous tests. This increase in salt concentration may have been the result of altered sluicing fluid properties caused by the addition of clay. Interestingly, had clay been present in the aerosol particles at the same mass ratio to $\mathrm{NaCl}$ as in the sluicing fluid, the dry aerosol mass concentration would have been about $45 \mathrm{mg} / \mathrm{m}^{3}$ rather than the $29 \mathrm{mg} / \mathrm{m}^{3}$ actually measured. The gravimetric results indicate that only about one-half as much clay (about $14 \mathrm{mg} / \mathrm{m}^{3}$ ) was present in the aerosol as might have been expected, based on the chloride results. The reason for this discrepancy is not known, but it is possible that the clay particles were agglomerated in the sluicing fluid and, therefore, less likely to disperse into the small droplets produced by the sluicing jet. A single filter sample obtained between 10 and $20 \mathrm{~min}$ after sluicing was stopped indicated a 3.6-fold decrease in. $\mathrm{NaCl}$ concentration over that interval.

Where the dry aerosol mass concentration was relatively easy to determine by drying the aerosol and collecting the salt and clay mass on filters, the determination of wet aerosol mass concentration was less successful. Wet aerosol concentrations of 220,220 , and $330 \mathrm{mg} / \mathrm{m}^{3}$ were estimated to have been present during Tests T01, T02, and T03, respectively, by assuming that the mass ratio of water to $\mathrm{NaCl}$ was the same in both the sluicing fluid and the aerosol droplets. Three other methods of measuring the wet aerosol mass concentration were not successful. First, attempts to compare the quantity of water collected in condensate and desiccant traps in the aerosol sample streams with the quantity of water calculated to be present in saturated conditions led to ambiguous results. This is because the amount of water vapor was much greater than that present in the mist droplets; the equilibrium vapor pressure is sensitive to temperature such that a 1 or $2^{\circ} \mathrm{C}$ error would completely change the result. The second method attempted was a comparison of the water content trapped downstream of the heated filter or impactor with the water content downstream of the unheated impactor sample. This approach failed because of test-to-test variations in condensate concentration. 
Finally, an attempt to compare the salt distributions in the unheated impactor with those in the heated impactor failed because of a probable non-log-normal size distribution of wet droplets at sizes exceeding $16 \mu \mathrm{m}$. Given a very long sample duration, the second approach may provide a method of measuring liquid water aerosol concentration with an acceptable level of accuracy.

Measurements of aerosol particle size distributions indicated that similar dry or residual particle sizes were present during all three tests. In addition, the results indicated that slightly smaller wet droplet sizes were present during Test T03. The aerodynamic mass median diameters (AMMD) of dried particles (measured in the heated cascade impactor) were 4 or $5 \mu \mathrm{m}$. During Tests T01 and T02, the AMMD of the wet, ambient-temperature aerosols (non-evaporated droplets) were greater than $16 \mu \mathrm{m}$. The measurement of larger AMMD exceeded the range of the impactors used, and would require measurement systems not used in the present study. During Test T03, the AMMD of the wet aerosol was slightly smaller at between 10 and $16 \mu \mathrm{m}$. In all cases, the distributions of particle sizes in the aerosols were very wide. For the dried particles, 80 and $30 \%$ of the particulate mass consisted of particies with acrodynamic diameters greater than 1 and $10 \mu \mathrm{m}$, respectively. The ambient-temperature, or wet aerosol, measurements indicated an even wider distribution of droplet sizes, with 80 to $90 \%$ of the mass consisting of droplets with aerodynamic diameters greater than $1 \mu \mathrm{m}$, and 60 to $70 \%$ of the mass consisting of droplets with sizes greater than $10 \mu \mathrm{m}$. Because of limitations inherent in the operation of particle impactors, additional stage-by-stage analysis of size distribution data (Appendix C) is not warranted.

\subsection{Video Camera Operations}

An in-tank camera was used to record a videotape of the tank interior to qualitatively study visibility during the tests. Color pictures of the tank interior and exterior associated with this work are provided in Appendix D. Deposition of salt or salt and clay to the camera lamps caused an apparent degradation of visibility that was not seen when the tank was observed directly through a plexiglass port. Consequently, visibility results are qualitative and reflect both types of observation.

Targets placed against the opposite tank wall at floor level were used to evaluate visibility. The targets, two sets of four painted circles of black on white and rust on gray, had diameters of 5.1, 2.5, 1.3 , and $0.63 \mathrm{~cm}(2.0,1.0,0.50$, and $0.25 \mathrm{in}$.). The diameters and color contrasts were selected to cover the range of visual resolution that may be needed during full-scale operations. The ability to discern the targets decreased as the tests progressed. Visibility was decreased almost immediately after the sluice jet was turned on and aimed. Again, the main source of this problem was associated with the obscuration of the camera lamps by deposition of mist on the lamps and the subsequent formation of a dry salt and clay film. The camera system was operated continuously during Test T01. Although visibility rapidly degraded using the camera, the fog was just barely visible by direct observation via the plexiglass post. During Test T01, the smallest target circles were barely visible through the camera within the first $8 \mathrm{~min}$. An hour later, only the largest two black circles could be seen. An hour and a half later, all visibility was obscured. During Tests T02 and T03, the camera system was operated intermittently in an attempt to alleviate the particle deposition to and obscuration of the lamps. This improved visibility during Test T02; the two largest circles could be seen throughout the test, and all targets could be seen $30 \mathrm{~min}$ after sluicing was stopped (indicating minimal attenuation of lamps and lens). However, during Test T03, the mixed salt and clay aerosol was sufficiently concentrated to cause poor visibility through both the camera and the plexiglass port. Within $30 \mathrm{~min}$, the smallest targets were just barely visible. Within less than an hour, all visibility within the tank was obscured (via the camera). The narration on the two videotapes describes times at which the different sized targets could be seen and when they could not. 
In-tank camera operation in the full-scale Tank C-106 is anticipated to use a system having engineered features to mitigate the problem associated with the buildup of solids encrusting the lens and camera lamps. The camera used in Tank C-106 will also be approximately four times higher above the surface of the waste and, thus, will be less impacted by spray and splash. If necessary, provisions will be made to use a quartz window with a washing system to cover components of the camera system. Based on experience in the scaled tank, and on consideration of the impact of backscatter, an additional recommendation is to separate the camera and light sources.

\subsection{Solution Analysis Data}

Grab samples of sluicing fluids were analyzed to determine total solids content. The grab samples from the first two tests were only analyzed for weight loss by drying because all solids present in the samples were dissolved solids $(\mathrm{NaCl})$. The grab samples from the third test, however, contained both dissolved solids $(\mathrm{NaCl})$ and undissolved solids (kaolin clay). A method that was used to separate these solids for analysis involved centrifuging an aliquot of the sample. The supernate was then dried to estimate the amount of dissolved salt that was present in the overall sample. IC analysis was also performed as a verification. After drying the entire sample,(a) the amount of kaolin clay in the overall sample was determined by subtracting the amount of salt (based on the amount of weight loss from drying and the salt to water ratio) from the total dried mass. Table 3.2 outlines the composition found in samples as a function of time. The table shows that the solids content resulting from analysis by drying and IC analysis was consistent. This discounts any possible error as a result of dissolved materials that may be collected during drying. Only one sample was analyzed for each of the first two tests because it was assumed any sample analyzed would be representative.

Table 3.2. Composition of Sluicing Fluid Grab Samples as a Function of Time. Overall solids are on a total mass basis. Salt-drying + salt-IC are on a salt and water basis excluding clay.

\begin{tabular}{|c|c|c|c|c|c|c|c|c|c|c|}
\hline & & & & & Test/Sam & & & & & \\
\hline & Test Tel & Test T02 & & & & Test & & & & \\
\hline Date & $7 / 2094$ & $7 / 21 / 94$ & $<-$ & & & $-7 r$ & $2 / 94$ & & & \\
\hline Time & $14: 32$ & $19: 03$ & $11: 22$ & $12: 40$ & $13: 00$ & $13: 24$ & $13: 47$ & $14: 07$ & $14: 27$ & $15: 00$ \\
\hline Sample ID & G03 & G05 & G0I & G02 & G03 & $\mathrm{GO4}$ & G05 & G06 & G07 & G08 \\
\hline $\begin{array}{c}\text { Composition (wt\%) } \\
\text { Salt-Drying (supernate) }\end{array}$ & N/A & N/A & 4.87 & 4.90 & 4.73 & 4.87 & 4.88 & 4.83 & 4.76 & 4.70 \\
\hline $\begin{array}{l}\text { Composition (wt\%) } \\
\text { Salt, IC (supemate) }\end{array}$ & N/A & N/A & 4.86 & 4.92 & 4.86 & 5.04 & 4.85 & 4.99 & 4.86 & 4.87 \\
\hline $\begin{array}{l}\text { Composition (wt\%) } \\
\text { Kaolin (overall) }\end{array}$ & None & None & 12.09 & 9.74 & 9.18 & 9.14 & 9.25 & 8.96 & 8.84 & 8.71 \\
\hline $\begin{array}{l}\text { Composition (wt\%) } \\
\text { Salt (overall) }\end{array}$ & 4.78 & 4.76 & 4.28 & 4.42 & 4.29 & 4.43 & 4.43 & 4.40 & 4.34 & 4.29 \\
\hline
\end{tabular}

(a) Drying the resultant solids layer after centrifuging showed that the aliquot was not representative of the grab sample taken. However, the weight percent salt in the supernate agreed well with the weight percent salt observed from samples taken from the first two tests. This suggests that the salt was uniformily and consistently dissolved in the solution throughout the three tests. 


\subsection{Flow Measurement Readings}

The flowmeter reading of the sluice stream and the ventilation velocity measured by the anemometer were recorded at 20 - to 30 -min intervals. The target settings of the anemometer and flowmeter were pre-determined based on scaling. Table 3.3 shows the average settings that were recorded for each test. These data sheets are also provided in Appendix B.

\subsection{Temperature Readings}

Data were recorded at 20 - to 30 -min intervals on separate data sheets to monitor temperatures and verify isokinetic sampling and saturated conditions. Temperatures included those of the sluice stream, head space, air inlet, and air temperatures before and after the HEPA filter. Table 3.4 shows the average thermocouple readings recorded for each test. The higher temperatures are directly attributable to the earlier time of day. The detailed data are provided on data sheets in Appendix B.

Table 3.3. Flow Measurement Readings Taken During Aerosol Testing

\begin{tabular}{|c|c|c|c|}
\hline Parameter & Test T01 (7/20/94) & Test T02 $(7 / 21 / 94)$ & Test T03 $(7 / 22 / 94)$ \\
\hline Start time & 21:04 & $16: 07$ & $12: 18$ \\
\hline Stop time & $24: 20$ & 19:59 & $15: 30$ \\
\hline Flowmeter reading, $\%$ & $55 \pm 0.20$ & $54.86 \pm 0.08$ & $55.54 \pm 0.23$ \\
\hline Flowmeter flow, gpm & 22.1 & 22.0 & 22.3 \\
\hline $\begin{array}{l}\text { Initial anemometer } \\
\text { velocity, fpm }\end{array}$ & $151.7 \pm 2.6$ & $157.5 \pm 3.4$ & $152.4 \pm 2.8$ \\
\hline $\begin{array}{l}\text { Corrected anemometer } \\
\text { flow, scfm }\end{array}$ & 18.7 & 19.2 & 18.6 \\
\hline
\end{tabular}

Table 3.4. Average Values of Thermocouple Readings Taken During Aerosol Testing

\begin{tabular}{ccccc} 
Parameter & Test T01 (7/20/94) & & Test T02 (7/21/94) & Test T03 (7/22/94) \\
\cline { 5 - 5 } Start Time & $21: 04$ & & $16: 07$ & $12: 18$ \\
Stop Time & $24: 20$ & & $19: 59$ & $15: 30$ \\
Sluice stream, ${ }^{\circ} \mathrm{C}$ & 25 & 26.9 & 27.1 \\
Head space, ${ }^{\circ} \mathrm{C}$ & 25.9 & 27.8 & 27.6 \\
Air inlet, ${ }^{\circ} \mathrm{C}$ & 47.2 & 49.3 & 52.3 \\
Before filter, ${ }^{\circ} \mathrm{C}$ & 26 & 28.5 & 28.6 \\
After filter, ${ }^{\circ} \mathrm{C}$ & 31.7 & 34.2 & 35.2
\end{tabular}




\subsection{Conclusions}

Test were performed that provided information useful to the ongoing evaluation of planned full-scale sluicing operations in Tank C-106. While data from the current tests appear consistent with predictions, additional studies are recommended, and actual aerosol concentrations should be confirmed during any full-scale operations. To provide additional information regarding the suitability of waste retrieval operations using other sluicing fluids or in other waste tanks, the procedures developed during the current study are recommended to be applied to tests using other sluicing targets, such as simulated sludge, and using more extensive variation of sluicing fluid and scaled ventilation flows.

For this study, a quarter-scale double-shell tank facility was modified by constructing an elevated false floor to provide a scaled version of Tank C-106. Other scaling considerations included ventilation flows, sluicing nozzle size and discharge rate, sluicing fluid characteristics, and test conditions. Based on the scaling relationships, a one-to-one correspondence is expected between the aerosol droplet mass flow rate exiting the test facility and the full-scale tank. Because of possible differences between the current test fluid and the future sluicing fluid actually selected for use in C-106, a relationship was developed that allows prediction of the aerosol mass concentration expected at the inlet of the ventilation system of the full-scale tank as a function of soluble and insoluble components in the sluicing fluid. For example, if buffered water is used in place of supernate from AY-101 to sluice waste in C-106, the source term predicted in this report should be reevaluated using the provided relationship.

Three scaled sluicing tests were performed using nominally $5 \mathrm{wt} \% \mathrm{NaCl}$ in water. The third test differed from the first two by the addition of kaolin clay to form a 4.4, 8.9, and $86.7 \mathrm{wt} \%$ solution of salt, clay, and water, respectively. The $0.64 \mathrm{~cm}$ diameter sluicing jet was targeted onto a flat metal plate during the first and third tests, and onto a surface of sluicing fluid during the second test. Sluicing jet operation was continuous during all tests. The characteristics of aerosols were measured in the exhaust flow duct leading away from the tank. A videocamera system was lowered into the tank in an attempt to determine visibility through the fogs generated in the vapor space as sluicing was per-

formed. Camera operation was affected by deposition of mist and formation of salt and clay films on the lamps; this led to apparent visibility degradation that was much greater than that observed directly. Actual attenuation of visibility was minimal during Tests T01 and T02 (salt) and much greater during Test T03 (salt and clay). It is recommended that additional engineering controls be added to camera systems installed in Tank C-106, and that other options such as intermittent operation of lamps and relocation of lamps away from the camera also be considered.

The dry aerosol mass concentrations in the exhaust flow (salt or salt and clay) were $10.6 \pm 0.5$, $10.5 \pm 0.4$, and $29.2 \pm 1.1 \mathrm{mg} / \mathrm{m}^{3}$ during Tests $\mathrm{T} 01, \mathrm{~T} 02$, and $\mathrm{T} 03$, respectively. The measurements, the average and standard deviation of four samples obtained in series, were initiated approximately 90 min after sluicing began and indicated steady conditions had developed within that time. Sampling continued until approximately 3 to $3.5 \mathrm{hr}$ after sluicing was initiated. Samples analyzed for chloride content indicated the concentration of $\mathrm{NaCl}$ in the aerosol was $11.2 \pm 0.2,10.9 \pm 0.0$, and $15.1 \pm 0.4 \mathrm{mg} / \mathrm{m}^{3}$ during Tests T01, T02, and T03, respectively. Subtracting the salt concentration from the total mass concentration, the concentration of clay in Test T03 was estimated to be $14.1 \pm$ $0.7 \mathrm{mg} / \mathrm{m}^{3}$. The reason for the 1.4-fold greater salt concentrations during Test T03 compared with Tests T01 and T02 was attributed to alteration of sluicing fluid characteristics by the addition of clay. It is not known why clay was present in the aerosol at a mass ratio to salt of approximately one-half 
of that in the sluicing fluid. It is speculated that this may have occurred because of the failure of small droplets to contain the relatively large, possibly agglomerated clay particles present in the sluicing fluid.

Wet aerosol mass concentrations in the exhaust flow (salt + clay + liquid water) were estimated using the mass of salt on dried aerosol samples to estimate the liquid water originally present. The wet aerosol mass concentrations during Tests T01, T02, and T03 were 220,220 , and $330 \mathrm{mg} / \mathrm{m}^{3}$, respectively. Measurement-based wet aerosol concentrations (based on gas temperatures, wet vs dry particle sizes, and quantities of water trapped downstream of aerosol samples) were not successful in providing direct indication of the wet aerosol mass. The main reason for the failure of the measurement-based approaches was the \pm 1 to $\pm 2^{\circ} \mathrm{C}$ uncertainty in gas temperature, which greatly influenced the estimated saturated water vapor content in the exhaust flow. A second reason for the failure of the measurement-based approaches was the presumed non-log-normal size distribution of wet droplets at sizes exceeding $16 \mu \mathrm{m}$. Given a very long sample duration and simultaneous heated and unheated samples, the second approach may provide a method of measuring liquid water aerosol concentration with an acceptable level of accuracy.

Measurements of aerosol particle size distributions indicated that while similar dry or residual particle sizes were present during all three tests, the wet droplet size present during Test T03 was slightly smaller than that during Tests T01 and T02. In summary, a total of 80 and $30 \%$ of the dryparticle mass consisted of particles with aerodynamic diameters greater than 1 and $10 \mu \mathrm{m}$, respectively. The ambient-temperature, or wet aerosol measurements, indicated an even wider distribution of droplet sizes, with 80 to $90 \%$ of the mass consisting of droplets with aerodynamic diameters greater than $1 \mu \mathrm{m}$, and 60 to $70 \%$ of the mass consisting of droplets with sizes greater than $10 \mu \mathrm{m}$.

Using scaling relationships developed to determine aerosol concentrations expected in Tank C-106 from the results in the pilot scale, assuming similar relative humidities (below), and using an example sluicing fluid that contains $10 \mathrm{wt} \%$ soluble and $10 \mathrm{wt} \%$ insoluble solids (and $80 \mathrm{wt} \%$ water), the full-scale dry and wet aerosol mass concentrations were predicted to be 1.9- and 1.1-fold greater than those measured in the pilot-scale study. Based on the dry and wet aerosol concentrations of 29 and $330 \mathrm{mg} / \mathrm{m}^{3}$ during Test T03 (the only test with both salt and clay) of the current pilot-scale study, the corresponding dry and wet aerosol concentrations in Tank C-106 with the assumed sluicing fluid composition would be 55 and $360 \mathrm{mg} / \mathrm{m}^{3}$, respectively. The increase in dry aerosol concentration would be due to an increase in soluble solids and slurry density, the slight change in wet concentration would be caused by density differences between pilot- and full-scale slurries. It should be noted that, because of the limited range of parameters tested in the current study, the further apart the difference between actual and pilot-scale fluid compositions, the more likely that the conversion from pilot- to full-scale would be affected by uncertainty.

Estimates of the aerosol characteristics expected during full-scale operations were based on the assumption that relative humidities in the headspace would be nearly saturated. Consideration of the effect of lower relative humidities indicated particle shrinkage could cause an $8 \%$ reduction in particle diameter at $90 \%$ relative humidity and a $37 \%$ reduction at $40 \%$ relative humidity. Such decreases in particle diameter, and the corresponding decrease in settling velocities, would cause the concentration of radionuclides in the tank headspace to increase. These amounts of shrinkage are estimated to result in increases in aerosol concentration by factors of 1.2 and 2.6 , at relative humidities of 90 and $40 \%$, respectively, compared to the initially generated particle sizes. The relative effect would be greater for more dilute sluicing solutions as the initially generated droplets would contain greater percentages of water and would evaporate to a greater degree before attaining equilibrium. Adjustments to the calculational method of estimating full-scale aerosol mass concentrations were not made based on relative humidity. Changes to the method would only be justified if there was a solid 
basis to expect low humidities during sluicing. This issue of particle shrinkage and increased concentration may become important if aerosol suppression techniques are employed that reduce the relative humidity during sluicing operations. 


\subsection{References}

Orr, C., Jr. 1966. Particulate Technology. The Macmillan Co., New York.

Ferlan, K. B. 1993. Tank 241-C-106 Sluicing Letter Report. WHC-SD-WM-ES-234, Rev. 2. Westinghouse Hanford Company, Richland, Washington. 


\section{Appendix A}

\section{Relative Humidity in Full-Scale Tank Headspace}




\section{Appendix A}

\section{Relative Humidity in Full-Scale Tank Headspace}

Two methods were used to estimate the relative humidity in the headspace of Tank C-106 (below). Differences in the assumptions and variables selected for the two methods reflects uncertainties associated with current data and plans for altering the ventilation system at the tank. Both methods rely on normal operating data (in the absence of sluicing). It is not known whether either method will accurately reflect actual conditions within the tank headspace during sluicing operations. However, it is likely that these methods would predict relative humidities equal to or less than those occurring during sluicing. The complex heat and mass transfer processes expected to be present during sluicing do not allow an analytical solution for humidity to be performed. In summary, the results of these evaluations suggest possible headspace relative humidities between about 55 and essentially $100 \%$. Calculations were performed to evaluate the potential effect of reduced relative humidity on aerosol concentration (Section 2.1.4). The calculations were performed over a broad range of possible relative humidities (40 to $100 \%$ ) that bracketed the results of the following estimates.

\section{A.1 Headspace Relative Humidity-Method One}

The relative humidity in the headspace of Tank C-106 was estimated based on the maximum amount of water the ventilation system could remove from the tank at the time of year that outside air has the lowest relative humidity (July). In the calculation, the total flow rate of the current ventilation system, $1020 \mathrm{scfm}$, was determined by adding the $860 \mathrm{scfm}$ recirculation loop flow rate to the $160 \mathrm{scfm}$ exhauster flow rate. One month was defined to equal 30 days.

Based on the calculations shown in the box, it can be seen that the ventilation system has the ability to remove approximately 6,350 gallons of water from the tank each month, assuming that the vapor entering the system is saturated. The current amount of water evaporated from the tank to maintain thermal equilibrium using the existing ventilation system is approximately 6,000 gallons per month. To remove this same amount of heat from the tank during sluicing operations, approximately the same amount of water will have to be evaporated. The air entering the ventilation system would need to be roughly $94 \%$ saturated to remove this volume of water, not considering the humidity additions caused by the action of the sluicing stream spray. As the high-heat solids are removed from the tank, the related heat reduction should be approximately offset by the heat additions caused by the sluice and slurry pumps. For these reasons, it appears to be a reasonable assumption that the air in the tank headspace will be at or near saturation during sluicing operations.

\section{A.2 Headspace Relative Humidity-Method Two}

The relative humidity in the headspace of Tank C-106 was estimated based on expected average conditions (historic psychrometric data), the new system design flow rate, and the assumed $6000 \mathrm{gal}$ per month water evaporation rate. In July, the average historic headspace temperature was $85.5^{\circ} \mathrm{F}$ when the average ventilation flow rate was $2000 \mathrm{cfm}$. At the new design flow rate of $1090 \mathrm{cfm}$, the expected temperature would be closer to $90.5^{\circ} \mathrm{F}$. 
Based on the calculations shown in the box, and depending on temperature, the relative humidity in the tank headspace is expected to be: $87 \%$ at $80^{\circ} \mathrm{F}, 74 \%$ at $85.5^{\circ} \mathrm{F}, 63 \%$ at $90.5^{\circ} \mathrm{F}$, and $54 \%$ at $95.5^{\circ} \mathrm{F}$.

\section{Method One Calculations}

\begin{tabular}{|c|}
\hline $\begin{array}{l}\text { Inlet air conditions (July average): } 75^{\circ} \mathrm{F}, 32 \% \mathrm{RH}\left(0.000441 \mathrm{lb} \mathrm{H}_{2} \mathrm{O} \text { per } \mathrm{ft}^{3} \mathrm{dry}^{\mathrm{air}} \text { ) }\right. \\
\text { Outlet air conditions (July average): } 80^{\circ} \mathrm{F}, 100 \% \mathrm{RH}\left(0.00164 \mathrm{lb} \mathrm{H}_{2} \mathrm{O} \text { per } \mathrm{ft}^{3} \mathrm{dry} \text { air) }\right. \\
\text { Change in water-carrying capacity: } 0.00164-0.000441=0.00120 \mathrm{lb} \mathrm{H}_{2} \mathrm{O} \text { per } \mathrm{ft}^{3} \mathrm{dry} \text { air } \\
\text { Current ventilation system water-removal capability calculation: } \\
\text { Condenser air flow rate: } \\
\text { (1020 scfm) } \times\left(43,200 \mathrm{~min} / \text { month) }=44,100,000 \mathrm{ft}^{3} / \text { month }\right. \\
\text { Maximum water removal rate in condenser: } \\
\left(0.00120 \mathrm{lb} \mathrm{H}_{2} \mathrm{O} \text { per } \mathrm{ft}^{3} \text { dry air }\right) \times\left(44,100,000 \mathrm{ft}^{3} \text { per month }\right)=52,900 \mathrm{lb} \mathrm{H}_{2} \mathrm{O} \text { per mon } \\
\left(52,900 \mathrm{lb} \mathrm{H}_{2} \mathrm{O} \text { per month) } \div\left(8.33 \mathrm{lb} \mathrm{H}_{2} \mathrm{O} \text { per gal } \mathrm{H}_{2} \mathrm{O}\right)=6,350 \text { gal } \mathrm{H}_{2} \mathrm{O} \text { per month. }\right.\end{array}$ \\
\hline
\end{tabular}

\section{Method Two Calculations}

\begin{tabular}{|c|}
\hline $\begin{aligned} \text { Recirculation air supply: } & 860 \mathrm{cfm} \text { at } 40.5^{\circ} \mathrm{F}, 100 \% \text { RH } \\
& \left(64.5 \mathrm{lb} \text { dry air per } \min , 0.335 \mathrm{lb} \mathrm{H}_{2} \mathrm{O} \text { per min) }\right.\end{aligned}$ \\
\hline $\begin{aligned} \text { Outside air supply: } & 230 \mathrm{cfm}, 0.107 \mathrm{lb} \mathrm{H}_{2} \mathrm{O} \text { per min } \\
& \left(17.3 \mathrm{lb} \text { dry air per min, } 0.107 \mathrm{lb} \mathrm{H}_{2} \mathrm{O} \text { per min) }\right.\end{aligned}$ \\
\hline Total air supply: $64.5+17.3=81.8 \mathrm{lb}$ dry air per min \\
\hline Water in total supply air mixture: $0.335+0.107=0.442 \mathrm{lb}_{2} \mathrm{O}$ per min \\
\hline Water evaporated at $6000 \mathrm{gal}$ per month: $1.15 \mathrm{lb} \mathrm{H}_{2} \mathrm{O}$ per min \\
\hline Total water in exhaust flow: $0.442+1.15=1.59 \mathrm{lb} \mathrm{H} \mathrm{H}_{2} \mathrm{O}$ per min \\
\hline Humidity ratio of exhaust flow $(\mathrm{H})$ : \\
\hline $\begin{array}{l}\mathrm{H}=\left(1.59 \mathrm{lb} \mathrm{H}_{2} \mathrm{O} \text { per min }\right) \div(81.8 \mathrm{lb} \text { dry air } / \mathrm{min}) \\
\mathrm{H}=0.0195 \mathrm{lb} \mathrm{H}_{2} \mathrm{O} \text { per lb dry air }\end{array}$ \\
\hline
\end{tabular}


Appendix B

\section{Data Tables}


Data Collected for

1/4-Scale Aerosol Testing

for Test T01

\begin{tabular}{|c|c|c|c|c|c|c|c|c|}
\hline Date & Time & $\begin{array}{c}\text { F-1 } \\
\text { Siuice } \\
\text { St. } \\
(\text { Flow \%) }\end{array}$ & Time & $\begin{array}{c}T-1 \\
\text { sluice } \\
\text { St. } \\
\left(\begin{array}{c}0 \\
(\end{array}\right)\end{array}$ & Time & $\begin{array}{c}T-2 \\
\text { Plenum } \\
\left(\begin{array}{c}{ }^{\circ} \\
C\end{array}\right)\end{array}$ & Time & $\begin{array}{l}\text { Air } \\
\text { Inlet } \\
\left(\begin{array}{c}{ }^{\circ} \\
C\end{array}\right)\end{array}$ \\
\hline \multirow[t]{7}{*}{$7 / 20 / 94$} & $\begin{array}{l}\text { 9:24 p.m. } \\
\text { 9:45 p.m. }\end{array}$ & $\begin{array}{l}55 \% \pm .2 \\
55 \% \pm .2\end{array}$ & $\begin{array}{l}9: 18 \text { p.m. } \\
9.50 \text { p.m. }\end{array}$ & $\begin{array}{l}25^{\circ} \mathrm{C} \\
25^{\circ} \mathrm{C}\end{array}$ & $\begin{array}{l}9: 18 \text { p.m. } \\
9: 52 \text { p.m. }\end{array}$ & $\begin{array}{l}26^{\circ} \mathrm{C} \\
26^{\circ} \mathrm{C}\end{array}$ & $\begin{array}{l}\text { 9:15 p.m. } \\
\text { 9:51 p.m. }\end{array}$ & $\begin{array}{l}48^{\circ} \mathrm{C} \\
49^{\circ} \mathrm{C}\end{array}$ \\
\hline & 10:04 p.m. & $55 \% \pm .2$ & 10:05 p.m. & $25^{\circ} \mathrm{C}$ & 10:09 p.m. & $26^{\circ} \mathrm{C}$ & 10:06 p.m. & $49^{\circ} \mathrm{C}$ \\
\hline & 10:24 p.m. & $55 \% \pm .2$ & 10:25 p.m. & $25^{\circ} \mathrm{C}$ & 10:27 p.m. & $26^{\circ} \mathrm{C}$ & 10:26 p.m. & $48^{\circ} \mathrm{C}$ \\
\hline & 10:44 p.m. & $55 \% \pm .2$ & 10:45 p.m. & $25^{\circ} \mathrm{C}$ & 10:47 p.m. & $26^{\circ} \mathrm{C}$ & 10:45 p.m. & $48^{\circ} \mathrm{C}$ \\
\hline & 11:04 p.m. & $55 \% \pm .2$ & 11:05 p.m. & $25^{\circ} \mathrm{C}$ & 11:05 p.m. & $26^{\circ} \mathrm{C}$ & 11:05 p.m. & $47^{\circ} \mathrm{C}$ \\
\hline & 11:24 p.m. & $55 \% \pm .2$ & 11:25 p.m. & $26^{\circ} \mathrm{C}$ & 11:25 p.m. & $26^{\circ} \mathrm{C}$ & 11:25 p.m. & $47^{\circ} \mathrm{C}$ \\
\hline & 11:44 p.m. & $55 \% \pm .2$ & 11:44 p.m. & $26^{\circ} \mathrm{C}$ & 11:45 p.m. & $26^{\circ} \mathrm{C}$ & 11:46 p.m. & $46^{\circ} \mathrm{C}$ \\
\hline \multirow[t]{2}{*}{$7 / 21 / 94$} & $\begin{array}{l}12: 04 \text { a.m. } \\
12: 24 \text { a.m. }\end{array}$ & $\begin{array}{c}55 \% \pm .2 \\
\ldots\end{array}$ & $\begin{array}{l}12: 05 \text { a.m. } \\
12: 25 \text { a.m. }\end{array}$ & $\begin{array}{l}26^{\circ} \mathrm{C} \\
25^{\circ} \mathrm{C}\end{array}$ & $\begin{array}{l}12: 05 \text { a.m. } \\
\text { 12:05 a.m. }\end{array}$ & $\begin{array}{l}26^{\circ} \mathrm{C} \\
26^{\circ} \mathrm{C}\end{array}$ & $\begin{array}{l}12: 05 \text { a.m. } \\
12: 25 \text { a.m. }\end{array}$ & $\begin{array}{l}45^{\circ} \mathrm{C} \\
46^{\circ}, \mathrm{C}\end{array}$ \\
\hline & $12: 44 \mathrm{a} . \mathrm{m}$. & -- & 12:44 a.m. & $25^{\circ} \mathrm{C}$ & $12: 45$ a.m. & $25^{\circ} \mathrm{C}$ & $12: 45$ a.m. & $46^{\circ} \mathrm{C}$ \\
\hline
\end{tabular}

Data Collected for

1/4-Scale Aerosol Testing

for Test TO1

\begin{tabular}{|c|c|c|c|c|c|c|}
\hline Date & Time & $\begin{array}{c}\text { T-4 Before } \\
\text { Filter } \\
\left({ }^{\circ} \mathrm{C}\right)\end{array}$ & Time & $\begin{array}{c}\text { T-5 After } \\
\text { Filter } \\
\left({ }^{\circ} \mathrm{C}\right)\end{array}$ & Time & $\begin{array}{c}\mathrm{F}-2 \\
\text { Anemo- } \\
\text { meter } \\
(\mathrm{fpm})\end{array}$ \\
\hline \multirow[t]{7}{*}{$7 / 20 / 94$} & $\begin{array}{l}\text { 9:19 p.m. } \\
\text { 9:51 p.m. }\end{array}$ & $\begin{array}{l}27^{\circ} \mathrm{C} \\
26^{\circ} \mathrm{C}\end{array}$ & $\begin{array}{l}\text { 9:20 p.m. } \\
\text { 9:51 p.m. }\end{array}$ & $\begin{array}{l}29^{\circ} \mathrm{C} \\
32^{\circ} \mathrm{C}\end{array}$ & $\begin{array}{l}\text { 9:21 p.m. } \\
\text { 9:54 p.m. }\end{array}$ & $\begin{array}{l}145 \\
151\end{array}$ \\
\hline & 10:07 p.m. & $26^{\circ} \mathrm{C}$ & 10:08 p.m. & $32^{\circ} \mathrm{C}$ & 10:10 p.m. & 152 \\
\hline & 10:26 p.m. & $26^{\circ} \mathrm{C}$ & 10:26 p.m. & $32^{\circ} \mathrm{C}$ & 10:28 p.m. & 152 \\
\hline & 10:46 p.m. & $26^{\circ} \mathrm{C}$ & 10:46 p.m. & $32^{\circ} \mathrm{C}$ & 10:48 p.m. & 152 \\
\hline & 11:05 p.m. & $26^{\circ} \mathrm{C}$ & 11:05 p.m. & $32^{\circ} \mathrm{C}$ & $11: 07$ p.m. & 152 \\
\hline & $11: 26$ p.m. & $26^{\circ} \mathrm{C}$ & 11:26 p.m. & $32^{\circ} \mathrm{C}$ & $11: 27$ p.m. & 153 \\
\hline & 11:46 p.m. & $26^{\circ} \mathrm{C}$ & 11:46 p.m. & $32^{\circ} \mathrm{C}$ & $11: 47$ p.m. & 150 \\
\hline \multirow[t]{2}{*}{$7 / 21 / 94$} & $\begin{array}{l}12: 07 \text { a.m. } \\
12: 05 \text { a.m. }\end{array}$ & $\begin{array}{l}26^{\circ} \mathrm{C} \\
26^{\circ} \mathrm{C}\end{array}$ & $\begin{array}{l}12: 07 \text { a.m. } \\
12: 05 \text { a.m. }\end{array}$ & $\begin{array}{l}32^{\circ} \mathrm{C} \\
32^{\circ} \mathrm{C}\end{array}$ & $\begin{array}{l}12: 09 \text { a.m. } \\
12: 26 \text { a.m. }\end{array}$ & $\begin{array}{l}153 \\
155\end{array}$ \\
\hline & $12: 45$ a.m. & $25^{\circ} \mathrm{C}$ & $12: 46$ a.m. & $32^{\circ} \mathrm{C}$ & $12: 48$ a.m. & 154 \\
\hline
\end{tabular}

B. 1 
Data Collected for

1/4-Scale Aerosol Testing

for Test T02

\begin{tabular}{|c|c|c|c|c|c|c|c|c|}
\hline Date & $\overline{\text { Time }}$ & $\begin{array}{c}\text { F-1 } \\
\text { Sluice } \\
\text { St. } \\
\text { (Flow \%) }\end{array}$ & Time & $\begin{array}{c}T-1 \\
\text { Sluice } \\
\text { St. } \\
\left({ }^{\circ} \mathrm{C}\right)\end{array}$ & Time & $\begin{array}{c}T-2 \\
\text { Plenum } \\
\left(\begin{array}{c}\left.{ }^{\circ} \mathrm{C}\right)\end{array}\right.\end{array}$ & Time & $\begin{array}{l}\text { Air } \\
\text { Inlet } \\
\left(\begin{array}{c}0 \\
0\end{array}\right)\end{array}$ \\
\hline \multirow[t]{11}{*}{$7 / 21 / 94$} & $\begin{array}{l}\text { 4:12 p.m. } \\
4: 33 \text { p.m. }\end{array}$ & $\begin{array}{l}55.0 \% \\
54.9 \%\end{array}$ & $\begin{array}{l}4: 16 \text { p.m. } \\
4: 34 \text { p.m. }\end{array}$ & $\begin{array}{l}26^{\circ} \mathrm{C} \\
26^{\circ} \mathrm{C}\end{array}$ & $\begin{array}{l}4: 18 \text { p.m. } \\
4: 36 \text { p.m. }\end{array}$ & $\begin{array}{l}28^{\circ} \mathrm{C} \\
27^{\circ} \mathrm{C}\end{array}$ & $\begin{array}{l}4: 15 \text { p.m. } \\
4: 34 \text { p.m. }\end{array}$ & $\begin{array}{ll}34^{\circ} \mathrm{C} \\
45^{\circ} \mathrm{C}\end{array}$ \\
\hline & 4:48 p.m. & $54.8 \%$ & 4:46 p.m. & $26^{\circ} \mathrm{C}$ & 4:47 p.m. & $27^{\circ} \mathrm{C}$ & $4: 46$ p.m. & $50^{\circ} \mathrm{C}$ \\
\hline & 5:07 p.m. & $54.9 \%$ & 5:09 p.m. & $27^{\circ} \mathrm{C}$ & 5:10 p.m. & $27^{\circ} \mathrm{C}$ & 5:09 p.m. & $52^{\circ} \mathrm{C}$ \\
\hline & 5:31 p.m. & $54.8 \%$ & 5:27 p.m. & $27^{\circ} \mathrm{C}$ & 5:29 p.m. & $28^{\circ} \mathrm{C}$ & 5:27 p.m. & $53^{\circ} \mathrm{C}$ \\
\hline & 5:49 p.m. & $54.8 \%$ & 5:51 p.m. & $27^{\circ} \mathrm{C}$ & 5:51 p.m. & $28^{\circ} \mathrm{C}$ & 5:51 p.m. & $52^{\circ} \mathrm{C}$ \\
\hline & 6:08 p.m. & $54.8 \%$ & 6:10 p.m. & $27^{\circ} \mathrm{C}$ & $6: 12$ p.m. & $28^{\circ} \mathrm{C}$ & $6: 10$ p.m. & $51^{\circ} \mathrm{C}$ \\
\hline & 6:27 p.m. & $54.8 \%$ & 6.28 p.m. & $27^{\circ} \mathrm{C}$ & $6: 29$ p.m. & $28^{\circ} \mathrm{C}$ & 6:28 p.m. & $51^{\circ} \mathrm{C}$ \\
\hline & 6:53 p.m. & $54.8 \%$ & 6:53 p.m. & $27^{\circ} \mathrm{C}$ & 6:54 p.m. & $28^{\circ} \mathrm{C}$ & 6:53 p.m. & $51^{\circ} \mathrm{C}$ \\
\hline & 7:18 p.m. & $55.0 \%$ & 7:20 p.m. & $28^{\circ} \mathrm{C}$ & 7:21 p.m. & $28^{\circ} \mathrm{C}$ & 7:20 p.m. & $51^{\circ} \mathrm{C}$ \\
\hline & 7:37 p.m. & $54.9 \%$ & 7:38 p.m. & $28^{\circ} \mathrm{C}$ & 7:39 p.m. & $28^{\circ} \mathrm{C}$ & 7:38 p.m. & $51^{\circ} \mathrm{C}$ \\
\hline & 7:59 p.m. & -- & 8:07 p.m. & $27^{\circ} \mathrm{C}$ & $8: 08$ p.m. & $28^{\circ} \mathrm{C}$ & $8: 07$ p.m. & $51^{\circ} \mathrm{C}$ \\
\hline
\end{tabular}

Data Collected for

1/4-Scale Aerosol Testing

for Test T02

\begin{tabular}{|c|c|c|c|c|c|c|}
\hline Date & Time & $\begin{array}{c}\text { T-4 Before } \\
\text { Filter } \\
\left({ }^{\circ} \mathrm{C}\right)\end{array}$ & Time & $\begin{array}{c}\text { T-5 After } \\
\text { Filter } \\
\left(\begin{array}{c}0 \\
\end{array}\right)\end{array}$ & Time & $\begin{array}{c}\mathrm{F}-2 \\
\text { Anemo- } \\
\text { meter } \\
(\mathrm{fpm})\end{array}$ \\
\hline \multirow[t]{11}{*}{$7 / 21 / 94$} & $\begin{array}{l}4: 15 \text { p.m. } \\
4: 35 \text { p.m. }\end{array}$ & $\begin{array}{l}31^{\circ} \mathrm{C} \\
29^{\circ} \mathrm{C}\end{array}$ & $\begin{array}{l}4: 14 \text { p.m. } \\
4: 35 \text { p.m. }\end{array}$ & $\begin{array}{l}33^{\circ} \mathrm{C} \\
36^{\circ} \mathrm{C}\end{array}$ & $\begin{array}{l}4: 13 \text { p.m. } \\
4: 34 \text { p.m. }\end{array}$ & $\begin{array}{l}155 \\
155\end{array}$ \\
\hline & 4:46 p.m. & $29^{\circ} \mathrm{C}$ & 4:46 p.m. & $35^{\circ} \mathrm{C}$ & $4: 48$ p.m. & 155 \\
\hline & 5:08 p.m. & $36^{\circ} \mathrm{C}$ & 5:09 p.m. & $34^{\circ} \mathrm{C}$ & 5:07 p.m. & 155 \\
\hline & 5:28 p.m. & $28^{\circ} \mathrm{C}$ & 5:28 p.m. & $34^{\circ} \mathrm{C}$ & 5:30 p.m. & 155 \\
\hline & 5:51 p.m. & $28^{\circ} \mathrm{C}$ & 5:51 p.m. & $34^{\circ} \mathrm{C}$ & 5:49 p.m & 155 \\
\hline & $6: 10 \mathrm{p} . \mathrm{m}$ & $28^{\circ} \mathrm{C}$ & 6:10 p.m. & $34^{\circ} \mathrm{C}$ & $6: 08$ p.m & 155 \\
\hline & $6: 28$ p.m. & $28^{\circ} \mathrm{C}$ & $6: 28$ p.m. & $34^{\circ} \mathrm{C}$ & 6:27 p.m. & 160 \\
\hline & 6:53 p.m. & $28^{\circ} \mathrm{C}$ & $6: 53$ p.m. & $34^{\circ} \mathrm{C}$ & 6:52 p.m. & 160 \\
\hline & $7: 20$ p.m. & $28^{\circ} \mathrm{C}$ & 7:20 p.m. & $34^{\circ} \mathrm{C}$ & 7:18 p.m. & 160 \\
\hline & 7:38 p.m. & $28^{\circ} \mathrm{C}$ & 7:38 p.m. & $34^{\circ} \mathrm{C}$ & 7:37 p.m. & 165 \\
\hline & 8:07 p.m. & $28^{\circ} \mathrm{C}$ & 8:07 p.m. & $34^{\circ} \mathrm{C}$ & 8:07 p.m. & 160 \\
\hline
\end{tabular}


Data Collected for

1/4-Scale Aerosol Testing

for Test T03

\begin{tabular}{|c|c|c|c|c|c|c|c|c|}
\hline Date & Time & $\begin{array}{c}\text { F-1 } \\
\text { Sluice St. } \\
\text { (Flow \%) }\end{array}$ & Time & $\begin{array}{c}T-1 \\
\text { Sluice } \\
\text { St. } \\
\left(\begin{array}{c}0 \\
(\end{array}\right)\end{array}$ & Time & $\begin{array}{c}\text { T-2 } \\
\text { Plenum } \\
\left(\begin{array}{cc}{ }^{\circ} & C\end{array}\right)\end{array}$ & Time & $\begin{array}{l}\text { Air } \\
\text { Inlet } \\
\left(\begin{array}{c}0 \\
0\end{array}\right)\end{array}$ \\
\hline \multirow[t]{10}{*}{$7 / 22 / 94$} & $\begin{array}{l}\text { 12:38 p.m. } \\
\text { 12:50 p.m. }\end{array}$ & $\begin{array}{l}55.5 \% \pm .2 \\
55.5 \% \pm .3\end{array}$ & $\begin{array}{l}12: 39 \text { p.m. } \\
12: 58 \text { p.m. }\end{array}$ & $\begin{array}{ll}26^{\circ} \mathrm{C} \\
27^{\circ} \mathrm{C}\end{array}$ & $\begin{array}{l}\text { 12:40 p.m. } \\
12: 59 \text { p.m. }\end{array}$ & $\begin{array}{l}27^{\circ} \mathrm{C} \\
27^{\circ} \mathrm{C}\end{array}$ & $\begin{array}{l}\text { 12:40 p.m. } \\
\text { 12:59 p.m. }\end{array}$ & $\begin{array}{l}51^{\circ} \mathrm{C} \\
51^{\circ} \mathrm{C}\end{array}$ \\
\hline & $1: 18$ p.m. & $55.4 \%=.3$ & 1:19 p.m. & $27^{\circ} \mathrm{C}$ & 1:19 p.m. & $27^{\circ} \mathrm{C}$ & $1: 19$ p.m. & $52^{\circ} \mathrm{C}$ \\
\hline & 1:38 p.m. & $55.7 \% \pm .6$ & $1: 38$ p.m. & $27^{\circ} \mathrm{C}$ & 1:38 p.m. & $27^{\circ} \mathrm{C}$ & 1:38 p.m. & $52^{\circ} \mathrm{C}$ \\
\hline & 1:58 p.m. & $55.7 \% \pm .5$ & 1:59 P.m & $27^{\circ} \mathrm{C}$ & 1:59 p.m. & $28^{\circ} \mathrm{C}$ & 1:59 p.m. & $53^{\circ} \mathrm{C}$ \\
\hline & 2:18 p.m. & $55.7 \% \pm .6$ & 2:19 p.m. & $27^{\circ} \mathrm{C}$ & 2:19 p.m. & $28^{\circ} \mathrm{C}$ & 2:19 p.m. & $52^{\circ} \mathrm{C}$ \\
\hline & 2:38 p.m. & $55.7 \% \pm .7$ & 2:39 p.m. & $27^{\circ} \mathrm{C}$ & 2:39 p.m. & $28^{\circ} \mathrm{C}$ & 2:39 p.m. & $52^{\circ} \mathrm{C}$ \\
\hline & 2:58 p.m. & $55.6 \% \pm .5$ & 2:59 p.m. & $28^{\circ} \mathrm{C}$ & 2:59 p.m. & $28^{\circ} \mathrm{C}$ & 2:59 p.m. & $53^{\circ} \mathrm{C}$ \\
\hline & $3: 18 \mathrm{p} . \mathrm{m}$ & $55.6 \% \pm .5$ & $3: 18$ p.m. & $28^{\circ} \mathrm{C}$ & $3: 18$ p.m. & $28^{\circ} \mathrm{C}$ & 3:18 p.m. & $52^{\circ} \mathrm{C}$ \\
\hline & $3: 38$ p.m. & -- & 3:38 p.m. & N.A. & 3:39 p.m. & $28^{\circ} \mathrm{C}$ & 3:39 p.m. & $53^{\circ} \mathrm{C}$ \\
\hline & 3:58 p.m. & -- & 3:58 p.m. & N.A. & 3:58 p.m. & $28^{\circ} \mathrm{C}$ & 3:58 p.m. & $54^{\circ} \mathrm{C}$ \\
\hline
\end{tabular}

\section{Data Collected for \\ 1/4-Scale Aerosol Testing \\ for Test T03}

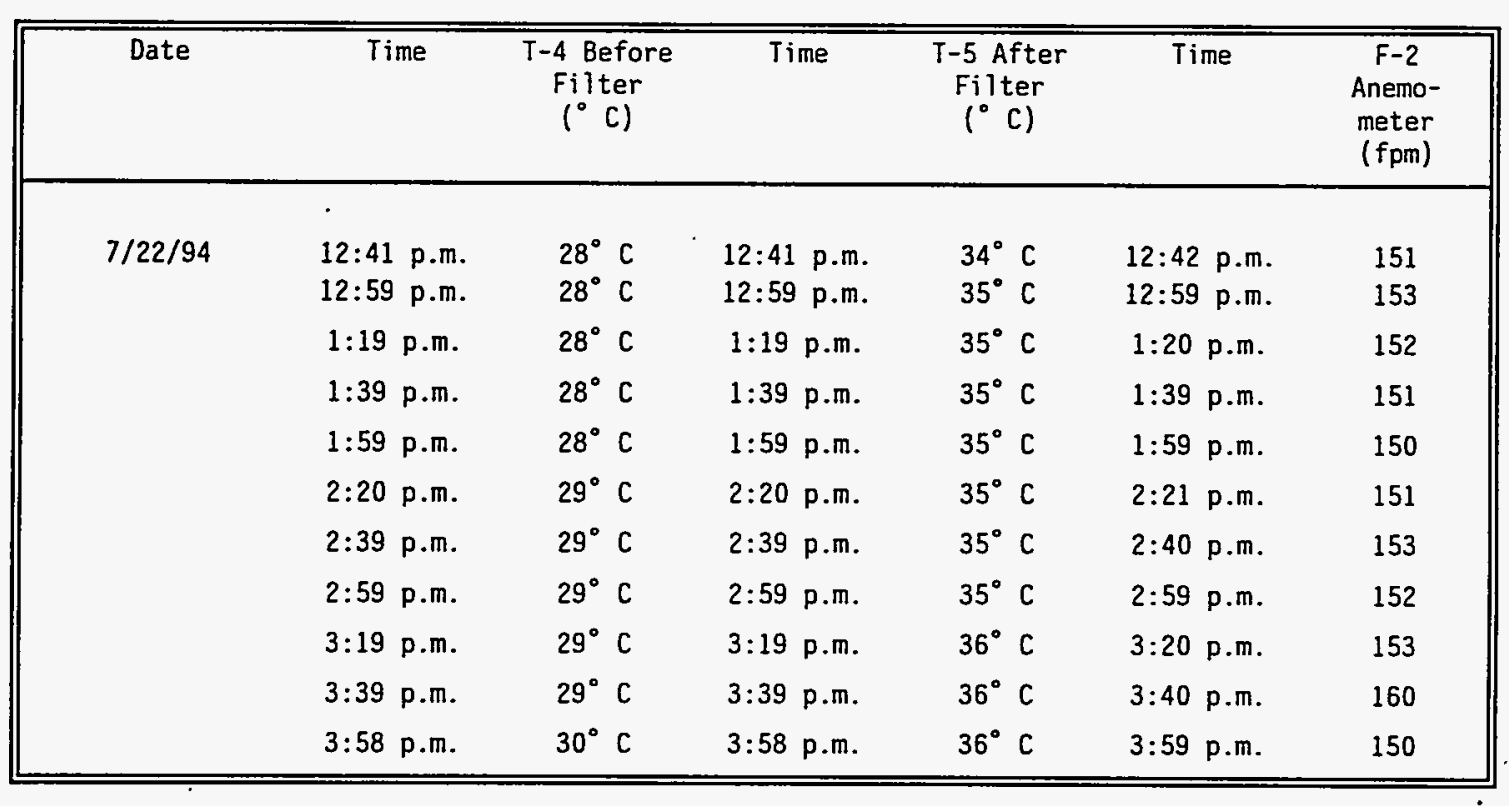




\section{Appendix C}

\section{Mass Concentration Results}


W320 Project Aerosol Test Data

\begin{tabular}{|c|c|c|c|c|c|c|c|c|c|c|}
\hline \multirow[b]{3}{*}{$\begin{array}{l}\text { Sample } \\
\text { Number }\end{array}$} & \multirow{3}{*}{$\begin{array}{c}\text { Solute } \\
\% \mathrm{NaCl} \\
(\%) \\
\end{array}$} & \multirow{3}{*}{$\begin{array}{c}\text { Sample } \\
\text { Volume } \\
\text { (L) }\end{array}$} & \multirow{3}{*}{$\begin{array}{c}\text { Mass } \\
\text { Collected } \\
(\mathrm{mg})\end{array}$} & \multirow{2}{*}{\multicolumn{3}{|c|}{ Blank-Corrected Analytical Results }} & \multirow{3}{*}{$\begin{array}{c}\text { Probe Loss } \\
\text { Correction } \\
\text { Factor } \\
\end{array}$} & \multicolumn{3}{|c|}{ Dry Aerosol Concentration } \\
\hline & & & & & & & & \multirow[b]{2}{*}{$\begin{array}{c}\text { Mass } \\
(\mathrm{mg} / \mathrm{m} 3)\end{array}$} & \multirow[b]{2}{*}{$\begin{array}{c}\mathrm{NaCl} \\
(\mathrm{mg} / \mathrm{m} 3)\end{array}$} & \multirow{2}{*}{$\begin{array}{c}\text { Estimated } \\
\text { Clay } \\
\text { (mg/m } 3 \text { ) }\end{array}$} \\
\hline & & & & $\begin{array}{c}\text { Chloride } \\
\text { (mg) }\end{array}$ & $\begin{array}{l}\mathrm{NaCl} \\
\text { (mg) }\end{array}$ & $\begin{array}{c}\% \text { of Mass } \\
(\%)\end{array}$ & & & & \\
\hline BFI & - & 0 & 0.00 & 0.066 & 0.109 & - & - & - & - & - \\
\hline $\mathrm{BF} 2$ & - & 0 & 0.01 & 0.065 & 0.107 & - & - & - & - & - \\
\hline \multicolumn{11}{|l|}{ Test Tol: } \\
\hline F0I & 100 & 130 & 1.28 & 0.840 & 1.385 & 108 & 1.049 & 10.3 & 11.2 & - \\
\hline F02 & 100 & 130 & 1.40 & 0.862 & 1.421 & 102 & 1.049 & 11.3 & 11.5 & - \\
\hline F03 & 100 & 130 & 1.30 & 0.840 & 1.385 & 107 & 1.049 & 10.5 & 11.2 & - \\
\hline \multirow[t]{3}{*}{ F04 } & 100 & 130 & 1.27 & 0.825 & 1.360 & 107 & 1.049 & 10.2 & 11.0 & - \\
\hline & & & & & & & Test T01 Average: & 10.6 & 11.2 & - \\
\hline & & & & & & & \pm 1 Std Dev: & 0.5 & 0.2 & - \\
\hline \multicolumn{11}{|l|}{ Test T02: } \\
\hline $\mathrm{Fol}$ & 100 & 260 & 2.66 & 1.655 & 2.729 & 103 & 1.035 & 10.6 & 10.9 & - \\
\hline F02 & 100 & 260 & 2.54 & 1.647 & 2.716 & 107 & 1.035 & 10.1 & 10.8 & - \\
\hline F03 & 100 & 260 & 2.68 & 1.661 & 2.739 & 102 & 1.035 & 10.7 & 10.9 & - \\
\hline \multirow[t]{3}{*}{ F04 } & 100 & 260 & 2.72 & 1.650 & 2.721 & 100 & 1.035 & 10.8 & 10.8 & - \\
\hline & & & & & & & Test T02 Average: & 10.5 & 10.9 & - \\
\hline & & & & & & & \pm 1 Std Dev: & 0.4 & 0.0 & - \\
\hline \multicolumn{11}{|l|}{ Test T03: } \\
\hline F01 & 32 & 130 & 3.50 & 1.111 & 1.832 & 52 & 1.044 & 28.1 & 14.7 & 13.4 \\
\hline F02 & 33 & 130 & 3.54 & 1.127 & 1.858 & 52 & 1.044 & 28.4 & 14.9 & 13.5 \\
\hline F03 & 33 & 130 & 3.70 & 1.141 & 1.881 & 51 & 1.044 & 29.7 & 15.1 & 14.6 \\
\hline F04 & 33 & 130 & 3.78 & 1.183 & 1.951 & 52 & 1.044 & 30.4 & 15.7 & 14.7 \\
\hline F05 & 33 & 130 & 0.52 & 0.325 & 0.536 & 103 & 1.044 & 4.2 & 4.3 & -0.1 \\
\hline \multirow[t]{3}{*}{ F06 } & 0 & 130 & -0.42 & 0.004 & 0.007 & - & 1.044 & -3.4 & 0.1 & \\
\hline & & & & & & & Test T03 Average: & 29.2 & 15.1 & 14.1 \\
\hline & & & & & & & \pm 1 Std Dev: & 1.1 & 0.4 & 0.7 \\
\hline \multicolumn{11}{|l|}{ Test TOL: } \\
\hline I01 & 100 & 130 & 1.55 & 0.801 & 1.321 & 85 & 1.049 & 12.5 & 10.7 & - \\
\hline 102 & 100 & 51 & 0.97 & 0.287 & 0.473 & 49 & 1.174 & 22.3 & 10.9 & - \\
\hline Test T02: & & & & & - & & & & & \\
\hline 101 & 100 & 260 & 3.03 & 1.556 & 2.566 & 85 & 1.035 & 12.1 & 10.2 & $\cdot$ \\
\hline 102 & 100 & 130 & 0.89 & 0.734 & 1.210 & 136 & 1.177 & 8.1 & 11.0 & - \\
\hline \multicolumn{11}{|l|}{ Test T03: } \\
\hline 102 & 50 & 130 & 3.70 & 0.945 & 1.558 & 42 & 1.044 & 29.7 & 12.5 & 17.2 \\
\hline 101 & 50 & 138 & 1.40 & 0.873 & 1.439 & 103 & 1.126 & 11.4 & 11.7 & -0.3 \\
\hline
\end{tabular}

C. 1 

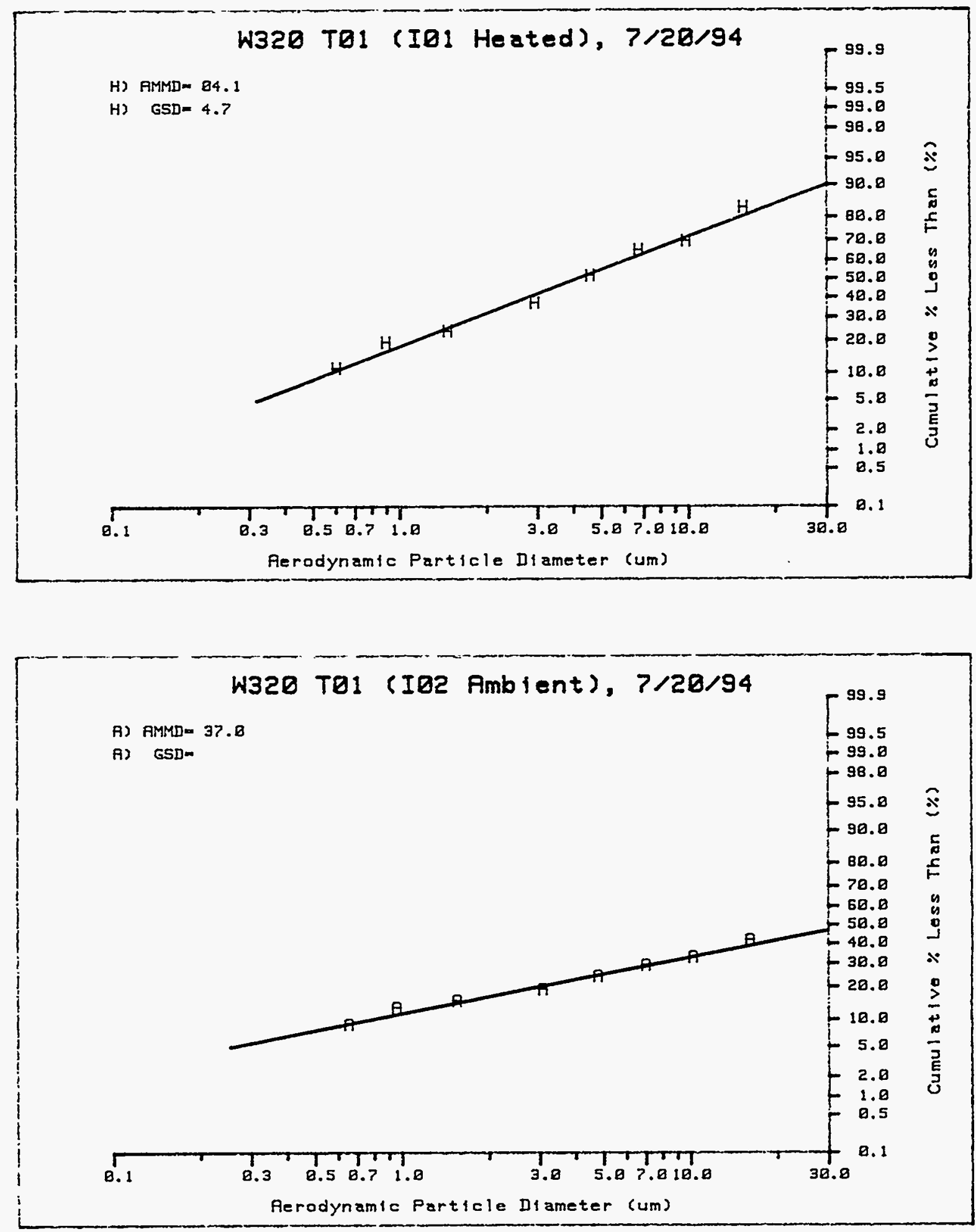

C. 2 

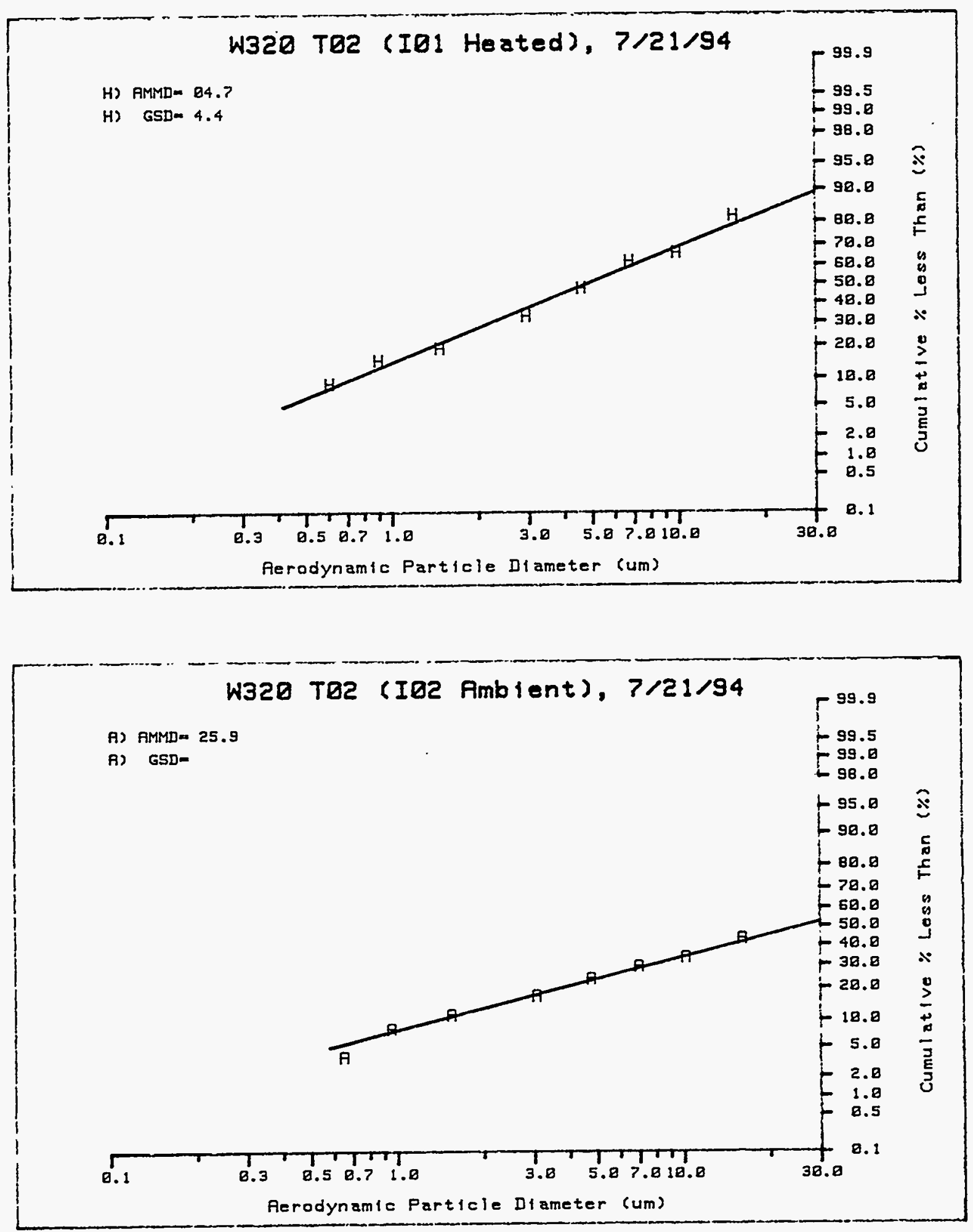

C. 3 

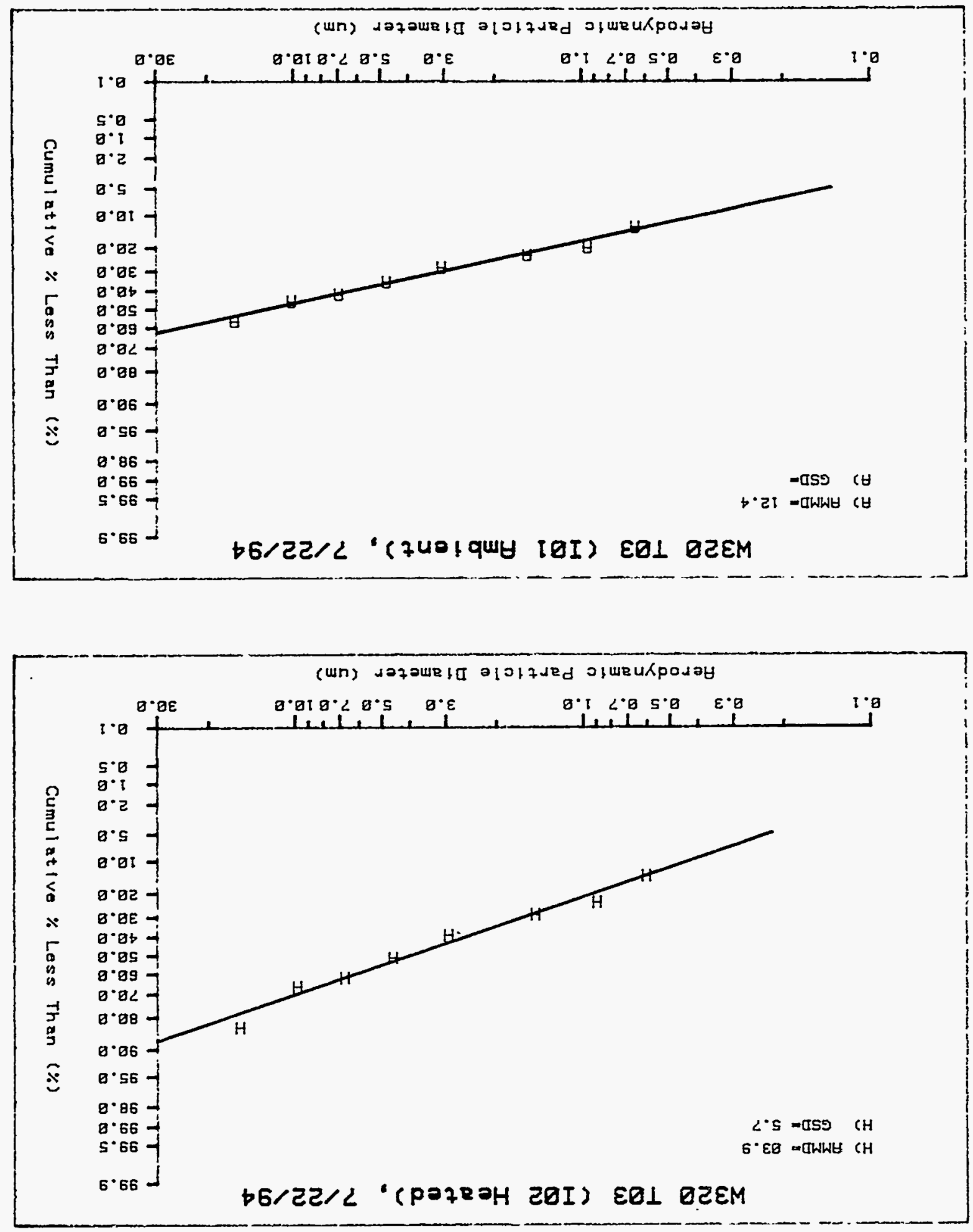
Date: $7 / 20 / 94$ Test \#W320 T01 I01 Heated

$T($ deg. $C)=100$

Sample Flow Rate $(\mathrm{lpm})=16.5$

Inlet Pressure $($ in $-\mathrm{H} 20)=0$

Pressure Drop $($ in-H2O $)=20$

Impactor ID number 1 , Number of 5 tages $=8$

$5 t k 50=.14$

\begin{tabular}{lccc} 
Stage No. & Load (mg) & $\begin{array}{c}\text { Cummulative } \\
\% \text { Less Than }\end{array}$ & D50 (um) \\
\hline 0 & 0.13 & 83.3 & 15.49 \\
1 & 0.11 & 69.4 & 9.82 \\
2 & 0.04 & 64.9 & 6.72 \\
3 & 0.11 & 51.4 & 4.58 \\
4 & 0.12 & 36.8 & 2.94 \\
5 & 0.11 & 23.7 & 1.47 \\
6 & 0.04 & 19.4 & 0.90 \\
7 & 0.07 & 11.2 & 0.60 \\
Backup Filter & 0.09 & -.0 & 0.00
\end{tabular}

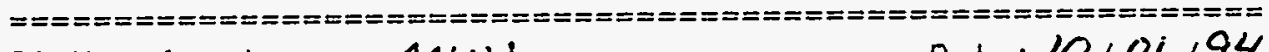
QA Verification:MUL_ Date: $10 / 0 \mathrm{O} / 94$ $A M M D=04.1 \quad G S D=4.7 \quad$ (Data Range: $5 \%-95 \%$ )

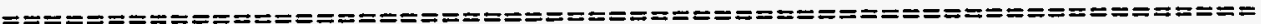

Date: $7 / 20 / 94$ Test \#W320 T01 I02 Ambient

$T($ deg. $C)=30$

Sample Flow Rate (lpm) $=13.3$

Inlet Pressure $($ in $-\mathrm{H} 2 \mathrm{O})=0$

Pressure Drop $(1 n-H 20)=20$

Impactor ID number 1 , Number of Stages $=8$

$5 t k .50=.14$

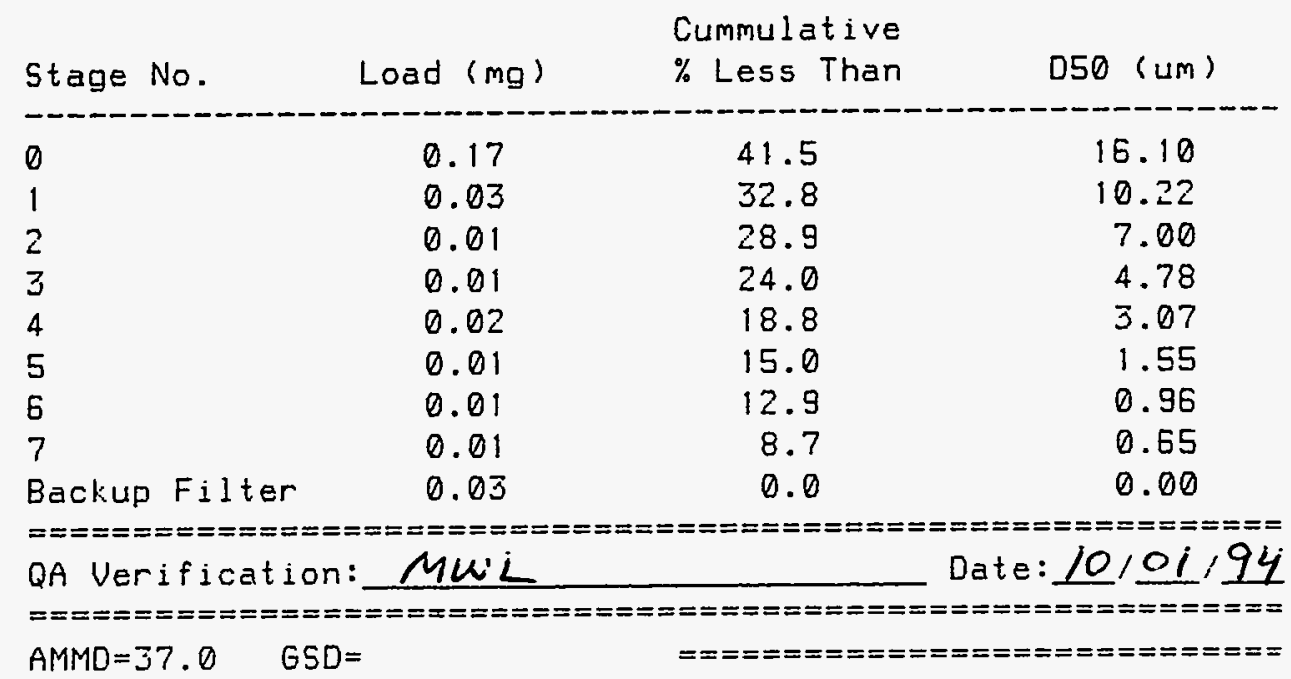


Date: $7 / 21 / 94$

Test \#W320 T02 I01 Heated

$T($ deg. $C)=100$

Sample Flow Rate $(1 \mathrm{pm})=16.5$

Inlet Pressure $\left(\right.$ in- $\left.\mathrm{H}_{2} \mathrm{O}\right)=0$

Fressure Drop $($ in $-\mathrm{H} 20)=20$

Impactor ID number 1 , Number of 5 tages $=8$

$\operatorname{sth} 50=.14$

Cummulat 1 ve

\begin{tabular}{lccc} 
Stage No. & Load (mg) & $\%$ Less Than & D50 (um) \\
\hline 0 & 0.28 & 81.9 & 15.49 \\
1 & 0.25 & 65.9 & 9.82 \\
2 & 0.06 & 61.8 & 6.72 \\
3 & 0.22 & 47.5 & 4.58 \\
4 & 0.23 & 35.0 & 2.94 \\
5 & 0.22 & 19.1 & 1.47 \\
6 & 0.06 & 15.1 & 0.90 \\
7 & 0.10 & 8.9 & 0.60 \\
Backup Filter & 0.14 & 0.0 & 0.00
\end{tabular}

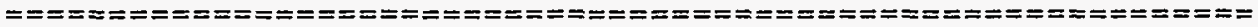
QA Verification: MWL

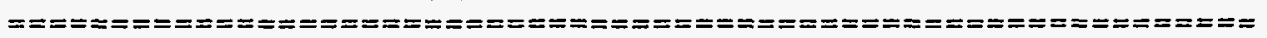
$A M M D=04.7 \quad G S D=4.4 \quad$ (Data Range: $5 \%-95 \%$ )

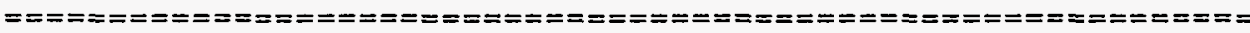

Date: $7 / 21 / 94$

Test \#W320 T02 I02 Ambient

$T($ deg. $C)=30$

Sample Flow Rate (lpm) $=13.3$

Inlet Pressure $($ in-H2O) $=0$

Pressure Drop $($ in $-\mathrm{H} 20)=20$

Impactor ID number 1, Number of Stages $=8$

$S t k 50=.14$

\begin{tabular}{lccc} 
Stage No. & Load (mg) & $\begin{array}{c}\text { Cummulative } \\
\text { \% Less Than }\end{array}$ & D50 (um) \\
\hline 0 & 0.42 & 42.9 & 16.10 \\
1 & 0.07 & 33.2 & 10.22 \\
2 & 0.03 & 28.9 & 7.00 \\
3 & 0.04 & 23.4 & 4.78 \\
4 & 0.05 & 16.9 & 3.07 \\
5 & 0.04 & 11.2 & 1.55 \\
6 & 0.02 & 7.9 & 0.96 \\
7 & 0.03 & 3.7 & 0.65 \\
Backup Filter & 0.03 & 0.0 & 0.00
\end{tabular}

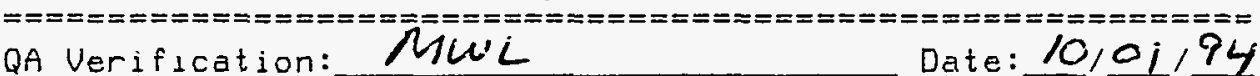

Date: $10,01,94$

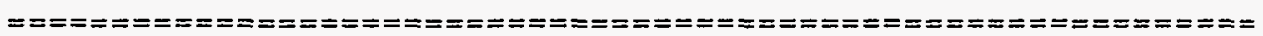
$A M M D=25.9 \quad 65 D=$

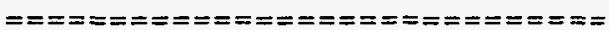


Date: $7 / 22 / 94$

Test \#W320 T03 I02 Heated

$T($ deg. $C)=100$

Sample Flow Rate $(1 \mathrm{pm})=16.5$

Inlet Pressure $(1 \mathrm{n}-\mathrm{HzO})=0$

Pressure Drop $(i n-H 20)=20$

Impactor ID number 1 , Number of 5 tages $=8$

Stk.50 = .14

\begin{tabular}{|c|c|c|c|}
\hline Stage No. & Load (mg) & $\begin{array}{l}\text { Cummulative } \\
\% \text { Less Than }\end{array}$ & 050 (um) \\
\hline 0 & 0.16 & 83.5 & 15.49 \\
\hline 1 & 0.16 & 66.3 & 9.82 \\
\hline 2 & 0.04 & 61.8 & 6.72 \\
\hline 3 & 0.10 & 51.2 & 4.58 \\
\hline 4 & 0.12 & 39.0 & 2.94 \\
\hline 5 & 0.10 & 28.9 & 1.47 \\
\hline 6 & 0.05 & 23.6 & 0.90 \\
\hline 7 & 0.09 & 14.1 & 0.60 \\
\hline Bachup Filter & 0.13 & 0.0 & 0.00 \\
\hline
\end{tabular}

QA Verification: Mwi Date:10101/94

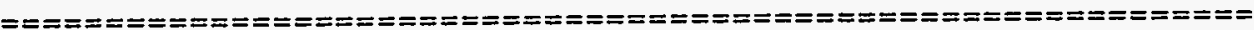

$A M M D=03.9 \quad G S D=5.7 \quad$ (Data Range: $5 \%-95 \%$ )

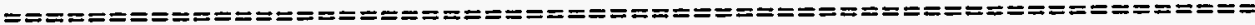

Date: $7 / 22 / 94$ Test \#W320 T03 I01 Ambient

$T(\operatorname{deg} . C)=30$

Sample Flow Rate $(\mathrm{lpm})=13.3$

Inlet Pressure $($ in $-\mathrm{H} 2 \mathrm{O})=0$

Pressure Drop $($ in $-\mathrm{H} 20)=20$

Impactor ID number 1 , Number of Stages $=8$

$\operatorname{stk} 50=.14$

\begin{tabular}{lccc} 
Stage No. & Load (mg) & $\begin{array}{c}\text { Cummulative } \\
\% \text { Less Than }\end{array}$ & 050 (um) \\
\hline 0 & 0.38 & 56.4 & 16.10 \\
1 & 0.09 & 45.6 & 10.22 \\
2 & 0.03 & 41.8 & 7.00 \\
3 & 0.06 & 35.4 & 4.78 \\
4 & 0.06 & 28.3 & 3.07 \\
5 & 0.05 & 23.0 & 1.55 \\
6 & 0.03 & 19.9 & 0.96 \\
7 & 0.06 & 13.2 & 0.65 \\
Bachup Filter & 0.12 & 0.0 & 0.00
\end{tabular}

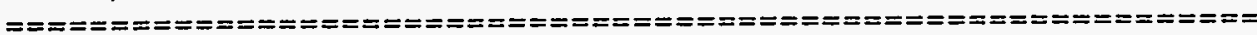
QA Verification: MWL Date:10/01/94

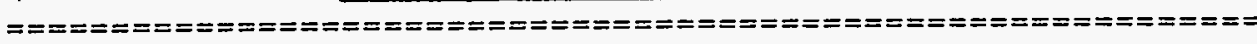
$A M M D=12.4 \quad 65 D=$ 


\section{Appendix D}

\section{Photographs}




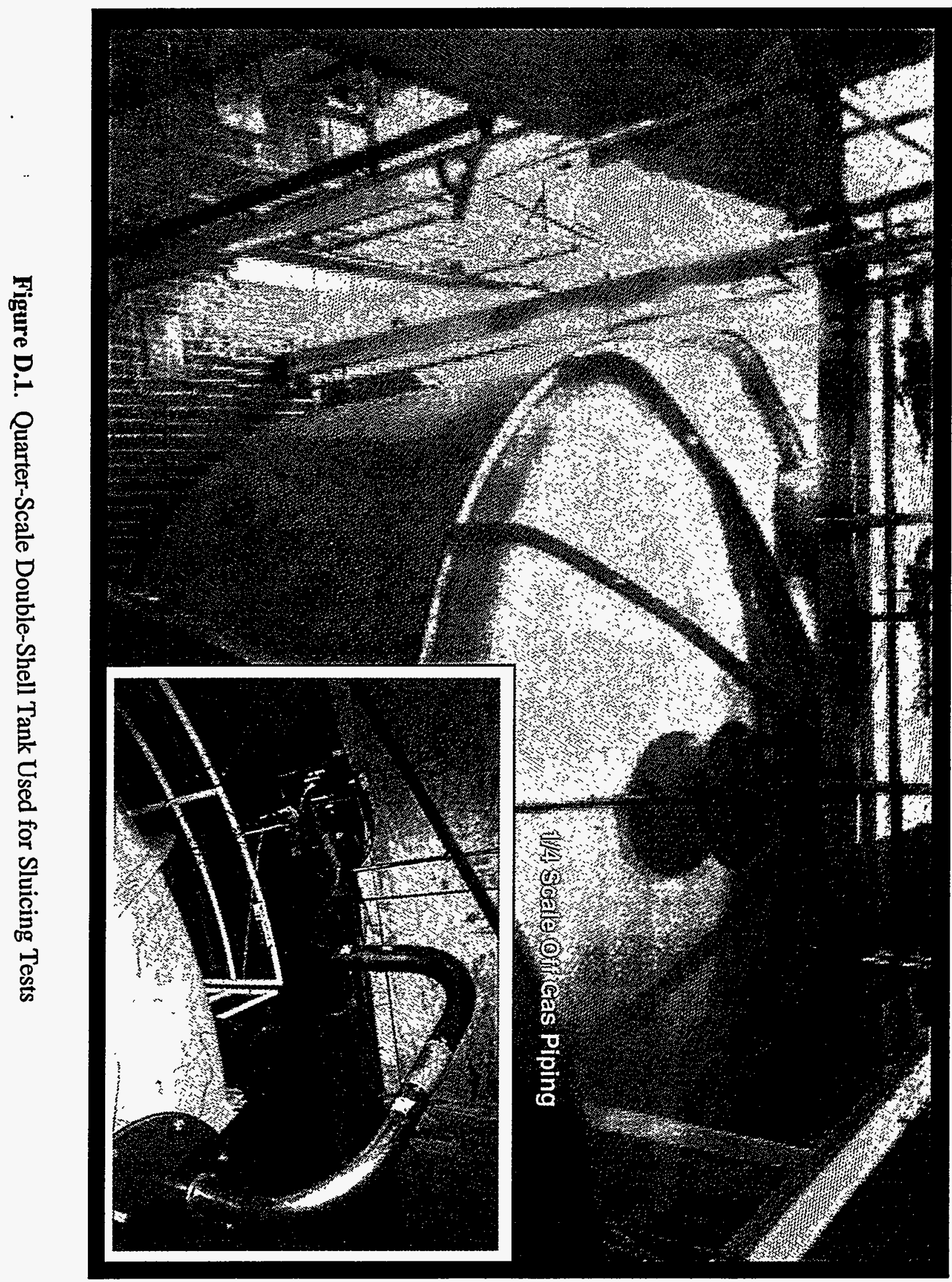




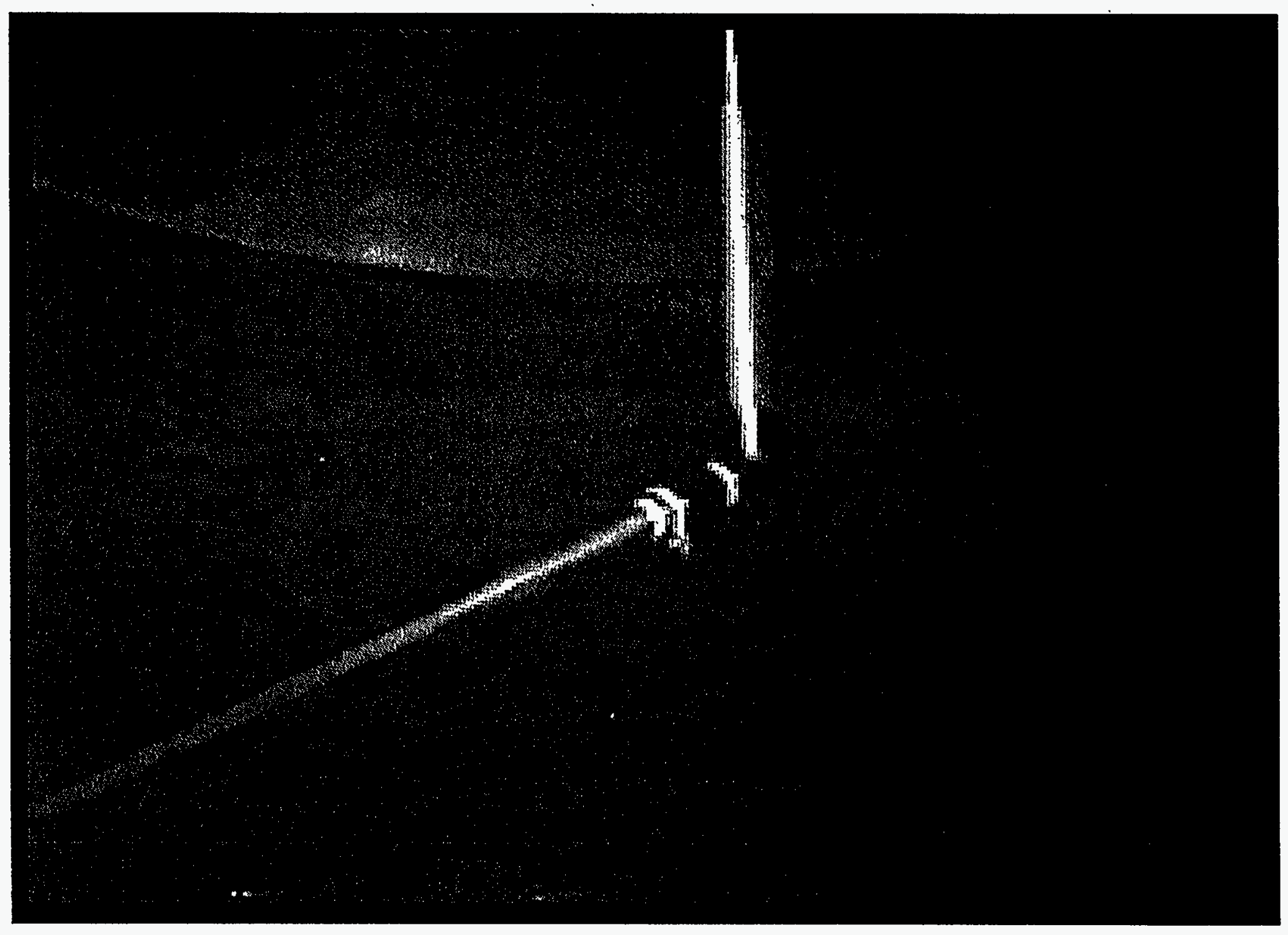

Figure D.2. Close-Up View of the 1/4-in. Sluicing Nozzle in Operation 


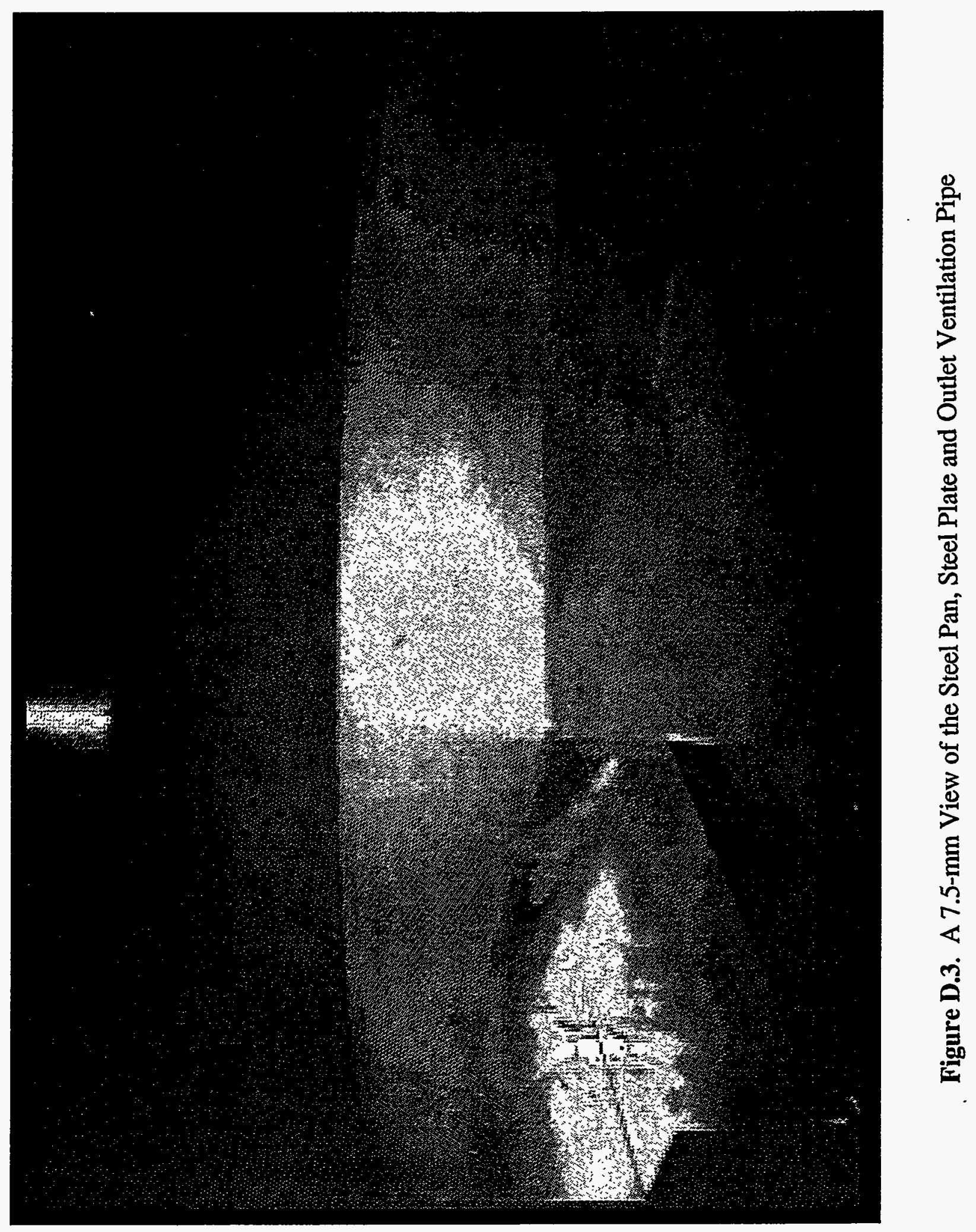

D. 3 


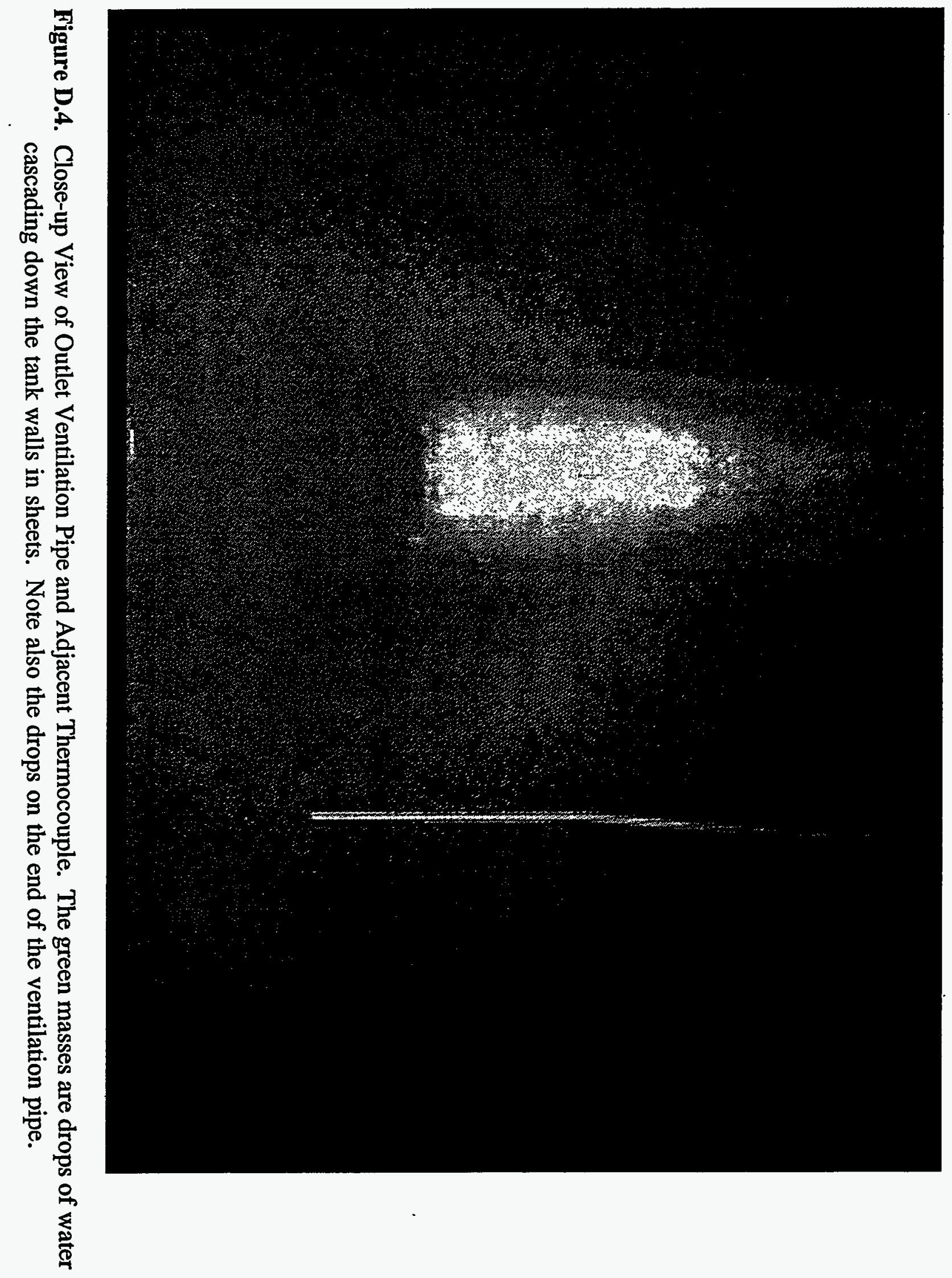




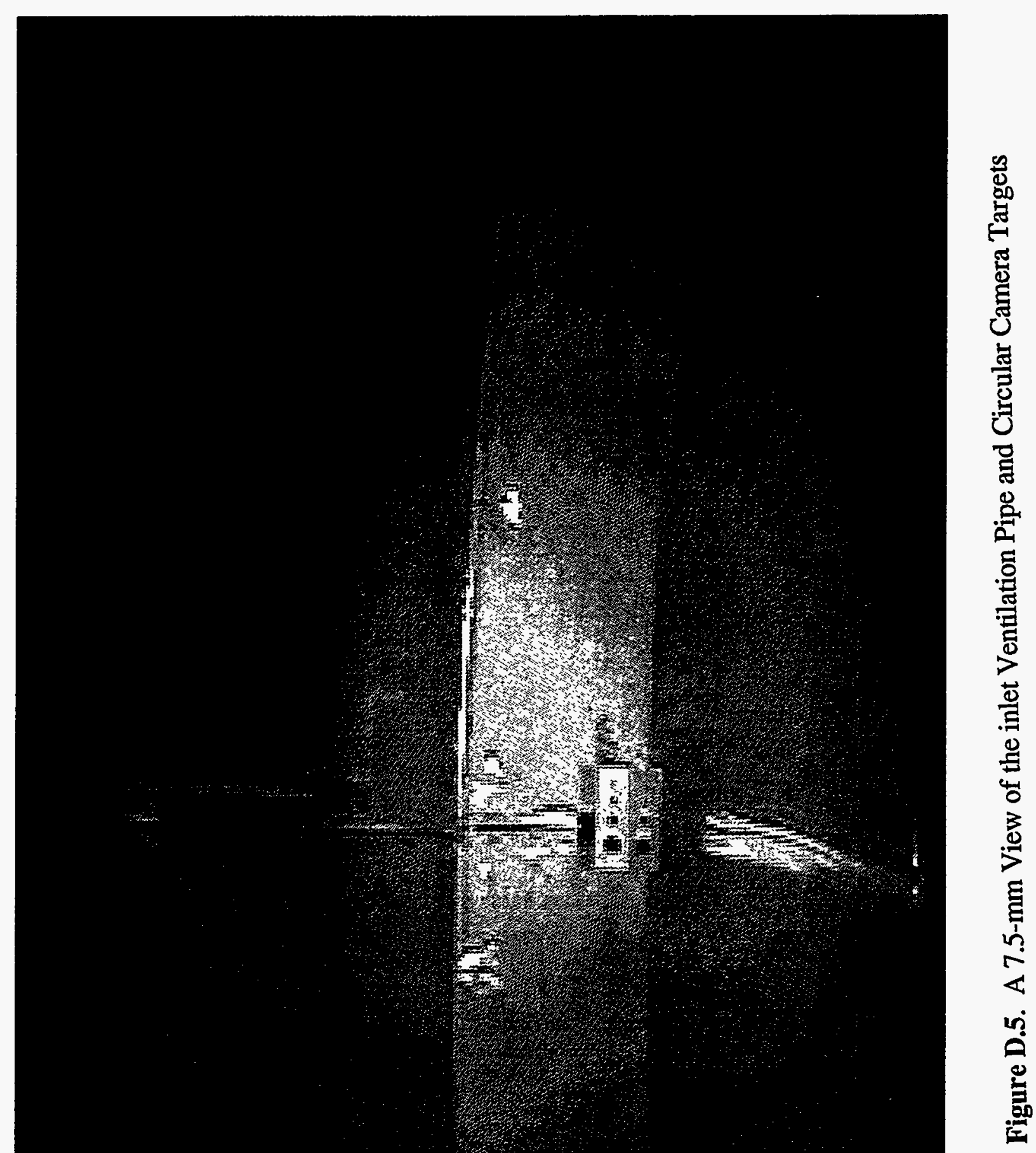

D. 5

-7-mpret, - 


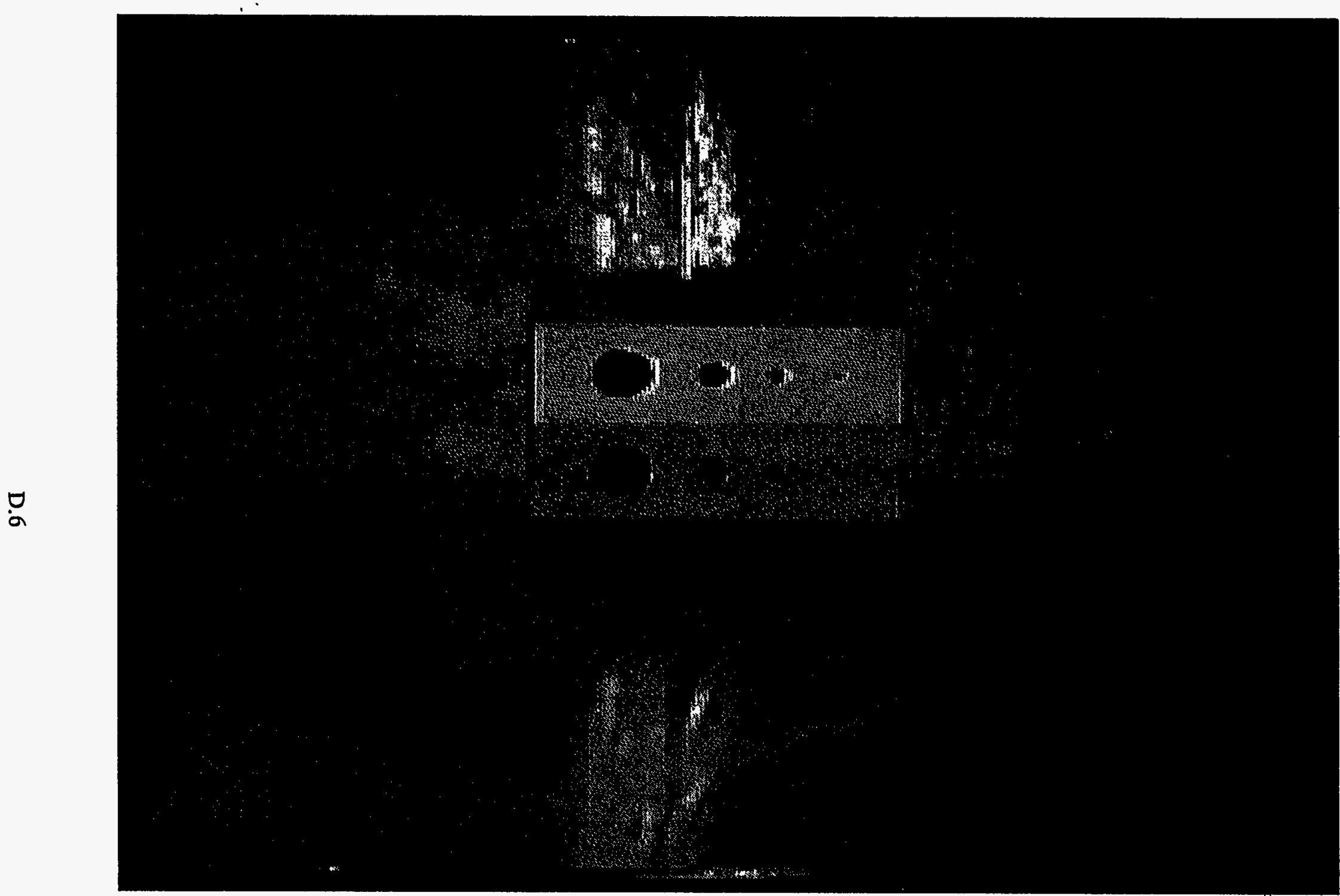

Figure D.6. Close-up View of the Circular Camera Targets for Evaluating Visibility 


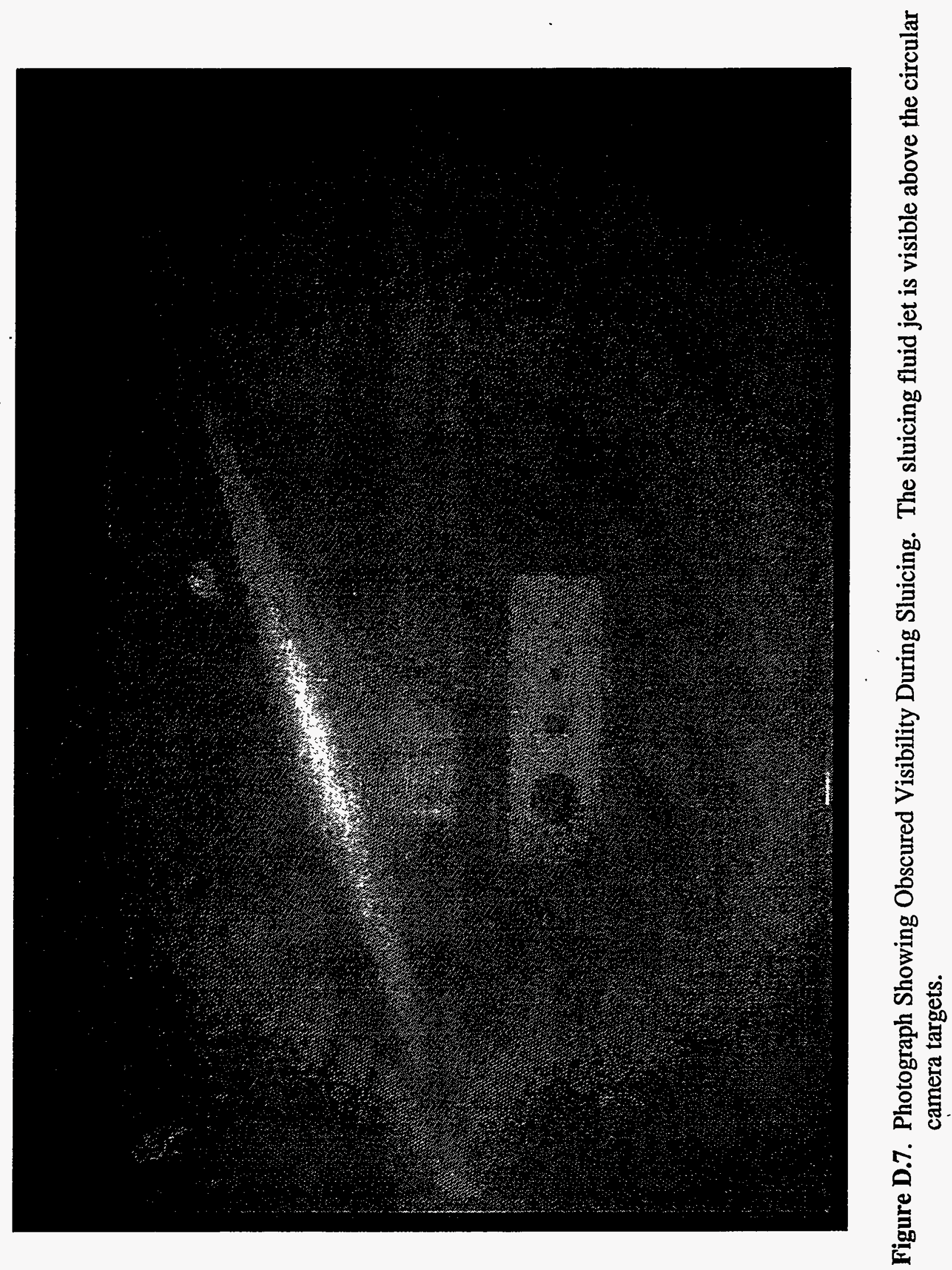

D. 7 


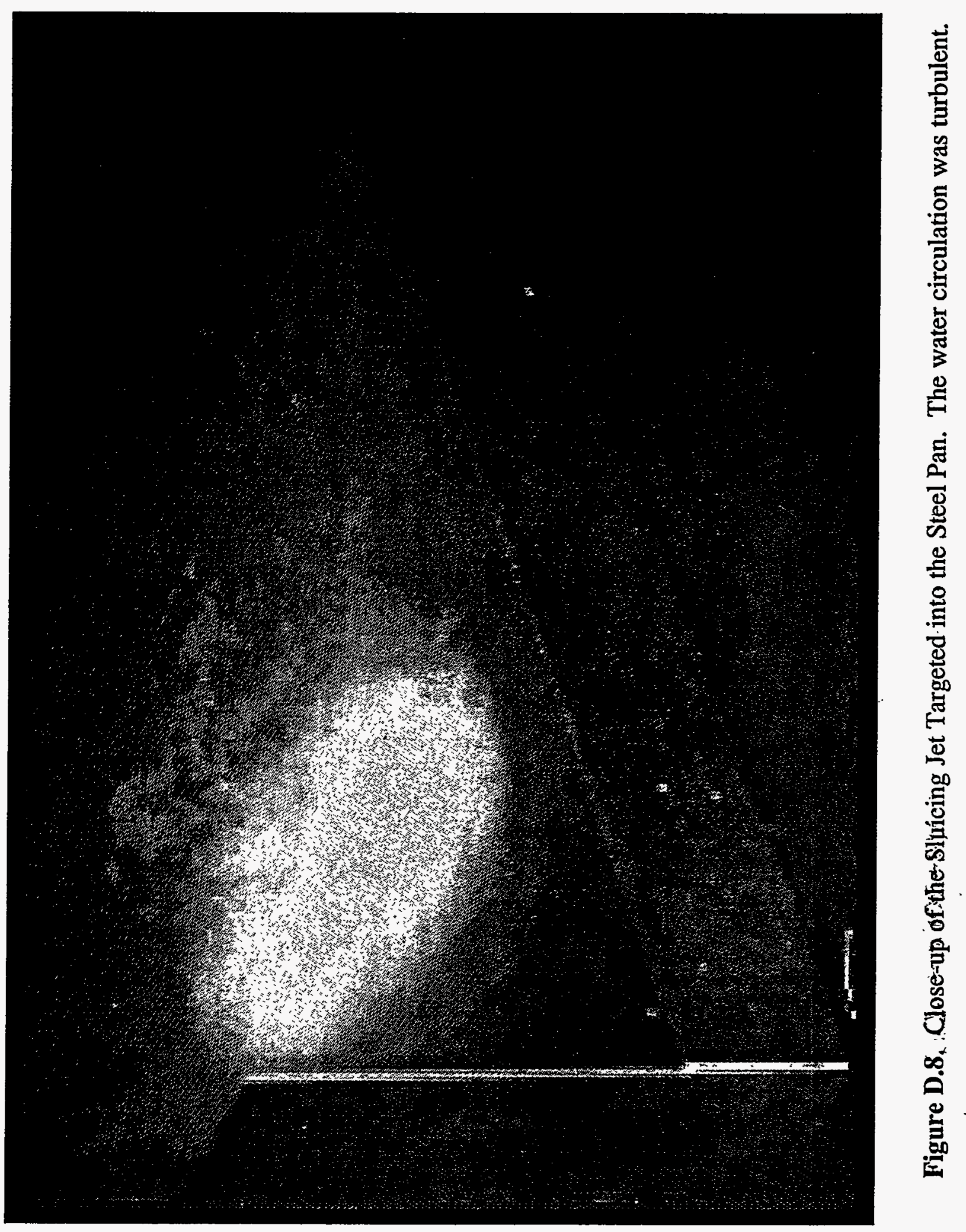

\section{8}




\section{Distribution}

No. of

Copies

Offsite

12 DOE/Office of Scientific and Technical Information

John Mocknick

U.S. Department of Energy

1000 Independence Avenue, S. W.

Washington, D.C. 20585

\section{Onsite}

4 DOE Richland Operations Office
S. T. Burnum
S7-53
P. E. Lamont
S7-53
H. Stafford
S7-53
W. R. Wrzesinski
S7-53

3 Kaiser Engineers Hanford

P. H. Langowski

R. F. Meisinger

S3-07

P. D. Rice

E6-46

E6-22
No. of

Copies

9 Westinghouse Hanford Company

J. P. Bailey (4)

S6-12

S. D. Estey

R2-11

D. B. Hagmann

S4-58

W. L. Knecht

S4-53

T. H. May

S6-12

E. J. Shen

S4-58

20 Pacific Northwest Laboratory

M. R. Beckette (2)

P7-19

S. L. Friant

K6-52

B. M. Johnson

K9-70

G. L. Ketner

P7-20

M. W. Ligotke (4)

E. V. Morrey

P7-59

P. A. Scott (2)

P7-19

G. A. Whyatt (2)

K9-73

Publishing Coordination

Technical Report Files (5)

Distr.1 